\title{
HNF1 $\alpha$ Controls Liver Lipid Metabolism and Insulin Resistance via Negatively Regulating the SOCS-3-STAT3 Signaling Pathway
}

\author{
Jiaorong Tan, ${ }^{1}$ Jiahong $\mathrm{Xu}^{2}{ }^{2}$ Guohua Wei, ${ }^{3}$ Lijuan Zhang, ${ }^{1}$ Long'e Sun, ${ }^{3}$ Guangyu Wang, \\ Fei Li, ${ }^{1}$ and Fengxiang Jiang $\mathbb{1}^{3}$ \\ ${ }^{1}$ Department of Endocrinology, People's Hospital of Shanghai Putuo, Tongji University School of Medicine, Shanghai 200060, China \\ ${ }^{2}$ Department of Cardiology, Tongji Hospital, Tongji University School of Medicine, Shanghai 200065, China \\ ${ }^{3}$ Department of Gastroenterology, People's Hospital of Shanghai Putuo, Tongji University School of Medicine, \\ Shanghai 200060, China
}

Correspondence should be addressed to Fengxiang Jiang; jiangfx205080@126.com

Received 21 October 2018; Revised 12 March 2019; Accepted 20 March 2019; Published 15 May 2019

Academic Editor: Ferdinando Carlo Sasso

Copyright ( 2019 Jiaorong Tan et al. This is an open access article distributed under the Creative Commons Attribution License, which permits unrestricted use, distribution, and reproduction in any medium, provided the original work is properly cited.

This study is aimed at evaluating the effects, functions, and mechanism of HNF1 $\alpha$ on hepatic glycolipid metabolism. In this study, free fatty acid- (FFA-) induced steatosis of hepatocyte liver cell LO2 was used as an in vitro model. The methods of Oil Red O staining, RT-qPCR, western blot, and immunofluorescence staining were used to detect LO2-regulated HNF1 $\alpha$ expression and its effects on FFA-induced LO2 cell steatosis, the insulin signaling and SOCS-3-STAT3 signaling pathways, the expression of lipid metabolism-related regulators, and phosphorylation. With increased FFA induction time, the expression of HNF1 $\alpha$ in the LO2 fatty degeneration hepatic cells gradually decreased. Downregulation of HNF1 $\alpha$ expression aggravated FFA-induced steatosis of LO2 hepatocytes. HNF1 $\alpha$ promotes activation of the insulin pathway and oxidative breakdown of fat and inhibits lipid anabolism. Inhibitors of STAT3 can reverse the regulation of decreased HNF1 $\alpha$ expression on the insulin signaling pathway and fat metabolism. We also confirmed this pathway using HNF1 $\alpha-/$ - mice combining treatment with STAT3 inhibitor NSC 74859 in vivo. HNF1 $\alpha$ regulates hepatic lipid metabolism by promoting the expression of SOCS-3 and negatively regulating the STAT3 signaling pathway.

\section{Introduction}

Nonalcoholic fatty liver disease (NAFLD) refers to a type of chronic liver disease characterized by excessive deposition of fat in hepatocytes that is not due to alcohol or other defined liver factors [1-6]. The liver is an important metabolic organ: after the food is degraded into glucose, fatty acids, and amino acids by the gastrointestinal tract, these products reach the liver through blood circulation where they are metabolized to provide energy for normal functioning. If liver metabolism is abnormal, it can cause harm to the body. In patients with NAFLD, excessive deposition of fat in liver cells not only affects the progression of other chronic liver diseases but may also lead to serious liver diseases such as cirrhosis and hepatocellular carcinoma. This increased understanding of the harmfulness of NAFLD has led some researchers to question whether it is correctly classified as benign lesions $[7,8]$. NAFLD is not only inextricably linked to the development of many liver diseases but also closely related to "metabolic syndromes" such as obesity and insulin resistance. Insulin resistance leads to a decrease in the efficiency of cellular uptake and utilization of glucose, resulting in a disorder of cellular glycolipid metabolism. Previous results showed that NAFLD is closely related to insulin resistance, which increases the risk of type 2 diabetes $[9,10]$. Given the close relationship between NAFLD, insulin resistance, and diabetes, the main components of metabolic syndrome, NAFLD is now commonly considered to be an important early warning signal for liver manifestations and metabolic syndromes. NAFLD is extremely harmful and has a high incidence. A meta-analysis showed that the prevalence of NAFLD is about $25 \%$ worldwide and about $27 \%$ 
in Asia [11]. With the increase in high-sugar and high-fat diets, the prevalence of NAFLD has shown a clear upward trend. It is possible that in the near future, NAFLD will become a severe disease worldwide.

Hepatocyte nuclear factor $1 \alpha(\mathrm{HNF} 1 \alpha)$ is a transcription factor mainly expressed in liver tissues, where it regulates the expression of multiple liver-specific genes and plays an important role in maintaining normal liver function. Mutations in the HNF1 $\alpha$ gene have been found in rare cases of hepatocellular adenomas, rare benign liver tumors, and noncirrhotic hepatocellular carcinomas [12]. In addition to liver tissue, HNF1 $\alpha$ is also expressed in the pancreas and kidneys. Mutations in the HNF1 $\alpha$ gene cause functional defects in islet $\beta$ cells and reduced insulin secretion, leading to maternal onset diabetes of the young 3 (MODY3) [13]. Previous work showed that lipid metabolism in patients with MODY3 differs from that of patients with type 2 diabetes and nondiabetic patients [14]. Patients with MODY3 also have elevated bile acid synthesis [15]. Double knockdown of the HNF1 $\alpha$ gene in mice causes multiple symptoms such as hepatomegaly, phenylketonuria, Fanconi syndrome, and noninsulin-dependent diabetes mellitus [16]. In summary, HNF $1 \alpha$ is involved in multiple metabolic pathways which play an important role in maintaining normal metabolism of the body. However, its regulation mechanism is still unclear.

Deletion of HNF1 $\alpha$ leads to increased secretion of inflammatory factors $[17,18]$. Chronic inflammation, especially visceral obesity, contributes to the development of metabolic diseases [19-21]. Many inflammatory factors are known to be involved in signal transduction by activating the STAT3 signaling pathway. The STAT3 signaling pathway functions in cell proliferation, differentiation, apoptosis, and immune regulation and thus is essential to maintaining the normal function of cells. However, the STAT3 signaling pathway is strictly regulated. SOCS3 is one of the important negative feedback regulators of the STAT3 signaling pathway. The effects of inflammatory factors or chronic inflammatory responses on metabolicrelated diseases such as NAFLD are associated with sustained activation of the STAT3 signaling pathway. Thus, the STAT3 signaling pathway is closely related to metabolic regulation and metabolism.

In this study, FFA-induced steatosis LO2 hepatocytes were used as an in vitro model to evaluate both the regulation of HNF $1 \alpha$ on hepatic lipid metabolism and the relationship between the HNF1 $\alpha$ and SOCS3-STAT3 signaling pathways. Our results provide both a powerful theoretical basis and new potential drug targets for the regulation of HNF $1 \alpha$ on hepatic lipid metabolism and treatment of nonalcoholic fatty liver.

\section{Materials and Methods}

2.1. Mouse Studies. C57/BL6 male mice were purchased from Shanghai Laboratory Animal Company (SLAC, Shanghai, China). HNF1a-/- mice were obtained from Charles River Laboratories and heterozygous mice were mated to obtain homozygous mutant mice as reported [22]; 8-week-old male mice were fed with either NC (protein 18.3\%, fat $10.2 \%$, carbohydrates $71.5 \%$, D12450B, Research Diets) or an HFD (protein 18.1\%, fat 61.6\%, carbohydrates $20.3 \%$, D12492, Research Diets) ad libitum for up to 8 weeks. Started at the 5 th week, indicated groups of mice were given NSC 74859 (Selleck), $5 \mathrm{mg} / \mathrm{kg}$, i.v. every 2 days for 5 doses. All animal procedures were approved by the Institutional Animal Care and Use Committee at People's Hospital of Shanghai Putuo, Tongji University School of Medicine. Mice were sacrificed at the 8th week, and the livers were taken for weight, Oil red $\mathrm{O}$ staining, or further analysis. Serum was collected for biochemical assays.

2.2. Culture of LO2 Cells. LO2 cells were purchased from The Cell Bank of Type Culture Collection of Chinese Academy of Sciences (Shanghai Institute of Cell Biology, Chinese Academy of Sciences, Shanghai, China). Cells were cultivated in RPMI-1640 medium (Hyclone, 11875093) supplemented with 10\% fetal bovine serum (Gibco, 10099141), 10,000 $\mathrm{U} / \mathrm{mL}$ penicillin, and $0.1 \mathrm{mg} / \mathrm{mL}$ streptomycin (Sigma, V900920) at $5 \% \mathrm{CO}_{2}, 37^{\circ} \mathrm{C}$.

2.3. Free Fatty Acid Induction of Lipolysis in LO2 Cells. The FFA solution was prepared by mixing $0.5 \mathrm{mM}$ oleic acid (Sigma, O7501) and $0.25 \mathrm{mM}$ palmitic acid (Sigma, P9767), LO2 cells were treated will FFA solution to induce steatosis in LO2 cells, and steatosis was detected at 12, 24, 36, and 48 $\mathrm{h}$ after the FFA treatment.

2.4. Oil Red O Staining. LO2 cells were fixed with $4 \%$ paraformaldehyde for $10 \mathrm{~min}$. After staining for $30 \mathrm{~min}$ with $60 \%$ Oil Red O (Sigma, O0625) isopropanol solution, they were washed with $60 \%$ isopropanol, and cell steatosis was observed under a microscope (Olympus). Frozen liver sections $(4 \mu \mathrm{m})$ were stained with Oil Red O (Sigma) for 30 minutes. The sections were counterstained with Mayer hematoxylin after destaining in $60 \%$ isopropanol.

2.5. Biochemical Assays. The contents of the LO2 cells and liver tissue triglyceride (TG) (Sigma, MAK266), cholesterol (TC) (Sigma, MAK043), and nonesterified fatty acid (NEFA) (Sigma, MAK044) were determined by using the corresponding kits and manufacturer's instructions using a microplate reader (Thermo Scientific). Serum glucose levels were measured with a glucometer (One Touch Ultra Easy, Life Scan). Serum fasting insulin was measured by ELISA (Millipore). The homeostasis model assessment of the IR index was calculated as $\mathrm{HOMA}-\mathrm{IR}=[\mathrm{FBG}(\mathrm{mmol} / \mathrm{l}) \times$ FIns (mIU/l)]/22.5.

2.6. RT-PCR Detection of $m R N A$ Levels. Total RNA was extracted by using TRIzol (Invitrogen), and the first strand of cDNA was reverse transcribed using a reverse transcription kit (Takara, 639522). Real-time quantitative PCR was performed using a PCR instrument (Bio-Rad) with the GAPDH as an internal reference using the One Step SYBR ${ }^{\circledR}$ PrimeScript $^{\text {TM }}$ RT-PCR Kit (Takara, RR066A). The primer sequences for HNF $1 \alpha$ fragment amplification are $5^{\prime}$-AACA CCTCAACAAGGGCACTC- $3^{\prime}$ and $5^{\prime}$-CCCCACTTGAA ACGGTTCCT- $3^{\prime}$, the primer sequences for SREBP-1C 
fragment amplification are $5^{\prime}$-ATCGGCGCGGAAGCTG TCGGGGTAGCGTC- ${ }^{\prime}$ and $5^{\prime}$-ACTGTCTTGGTTGTTG ATGAGCTGGAGCAT- $3^{\prime}$, the primer sequences for PPAR fragment amplification are $5^{\prime}$-CAAGTGCCTTTCTGTC GG-3' and $5^{\prime}$-TGTTTCCATCTTCGCTGT- ${ }^{\prime}$, and the primer sequences for GAPDH internal reference are $5^{\prime}$ -ACAACTTTGGTATCGTGGAAGG-3' and $5^{\prime}$-GCCATC ACGCCACAGTTTC-3'.

2.7. WB Detection. The total cellular or liver tissue protein was obtained by lysing the cells with RIPA lysate (Sigma, V900854), and the protein concentration was determined using a BCA protein concentration assay kit (Sigma, FP0010). Equal amounts of protein were electrophoresed on a $10 \%$ Bis-Tris gel at $120 \mathrm{~V}$ for $1 \mathrm{~h}$, the protein was transferred to the PVDF membrane at $350 \mathrm{~mA}$ for 70 minutes, and the PVDF membrane was blocked with 5\% BSA in TBST buffer for $1 \mathrm{~h}$. The primary antibody was incubated by gentle shaking at $4^{\circ} \mathrm{C}$ overnight, and the secondary antibody was incubated for $1 \mathrm{~h}$ at room temperature. ECL hypersensitive luminescent solution (Thermo, 32132) was used for color reaction, and gray scale was detected by image laboratory software (BioRad) to quantitatively analyze protein expression. The antibodies used included HNF1 $\alpha$ antibody (Abcam, ab96777), IRS-1 antibody (CST, \#2382), phospho-IRS-1 antibody (CST, \#2385), AKT antibody (CST, \#9272), phospho-Akt antibody (CST, \#4060), SOCS3 antibody (CST, \#2932), STAT3 antibody (CST, \#9139), phospho-STAT3 (CST, \#9134), SREBP1 antibody (Abcam, ab191857), and PPAR $\alpha$ antibody (Abcam, ab8934). The GAPDH protein antibody (Abcam, ab8245) was selected as an internal reference.

2.8. Immunofluorescence Staining. Cells were fixed with $4 \%$ paraformaldehyde (Sigma, 158127) for $10 \mathrm{~min}$, permeated with $0.5 \%$ Triton X-100 in PBS for 20 min at room temperature, and then, the cells were blocked with 5\% BSA for $1 \mathrm{~h}$. HNF1 $\alpha$ antibody (Abcam, ab96777) was added and incubated overnight at $4^{\circ} \mathrm{C}$. Fluorescent secondary antibody (Abcam, ab150077) was added for $2 \mathrm{~h}$ at room temperature. Cells were then incubated with DAPI for $10 \mathrm{~min}$ at room temperature and observed using a fluorescence microscope (Nikon).

2.9. HNF1 $\alpha$ Overexpression and Knockdown Vector Construction. A 1893 bp HNF1 $\alpha$ cDNA fragment was obtained by RT-PCR and cloned into the pcDNA3.1 vector (addgene) to construct an HNF1 $\alpha$ expression vector. The shRNA sequence CCGGAGACTGCAGAAGTACCC TCAACTCGAGTTGAGGGTACTTCTGCAGTCTTTTTTTG was inserted into the pGPU6/Neo vector (GenePharma, Shanghai, China) to construct an HNF1 $\alpha$ RNAi interference vector.

2.10. Data Analysis. Statistical analysis was performed using SPSS16.0 software, using the Student $t$-test with $p<0.05$ considered a significant difference.

\section{Results}

3.1. FFA Induces the Degeneration of LO2 Cells to Decrease the Expression of HNF1 $\alpha$. The results of Oil Red O staining showed that the amount of red granular lipid droplets in LO2 cells gradually increased and the fatty degeneration gradually increased with the extension of the time for the FFA treatment (Figure 1(a)). The results of biochemical indicators showed that the total cholesterol (TG), triglyceride (TC), and nonesterified fatty acid (NEFA) levels of LO2 cells showed a significant upward trend with increasing FFA treatment time (Figure 1(b)). The results of RT-qPCR, western blot, and fluorescent immunoassay showed that the fatty degeneration of LO2 cells increased with FFA treatment time, and the mRNA and protein expression of HNF1 $\alpha$ showed a significant downward trend (Figures 1(c) and 1(d)).

3.2. HNF1 $\alpha$ Inhibits FFA-Induced Fatty Degeneration in LO2 Cells. To determine whether HNF1 $\alpha$ affects FFA-induced steatosis of hepatocyte $\mathrm{LO} 2$, overexpression vectors and shRNA knockdown vectors were used to regulate HNF1 $\alpha$ expression. All of the above vectors are capable of efficiently regulating mRNA and protein expression levels (Figures 2(a) and 2(b)).

The results of Oil Red O staining showed that after upregulating the expression of HNF1 $\alpha$, the number of red granular lipid droplets in LFA-induced LO2 cells decreased and steatosis was reduced when compared to the control. By downregulating the expression of HNF $1 \alpha$, FFA induction increased the number of red granular lipid droplets in $\mathrm{LO} 2$ cells and aggravated fatty degeneration (Figure 3(a)). Compared with the control, upregulation of HNF $1 \alpha$ expression in the FFA-induced LO2 cells significantly decreased the content of TG, TC, and NEFA, while downregulation increased them (Figures 3(b)-3(d)).

3.3. HNF1 $\alpha$ Promotes Activation of the Insulin Signaling Pathway. In order to evaluate the effect of HNF1 $\alpha$ on the insulin signaling pathway, two important regulatory factors, IRS-1 and AKT, were selected as representatives in this pathway. Western blot analysis showed that FFA-induced phosphorylation of IRS-1 and AKT in LO2 cells was significantly increased after the upregulation of HNF1 $\alpha$ expression, whereas FFA-induced IRS-1 and AKT in LO2 cells were downregulated after the HNF1 $\alpha$ expression was downregulated. The phosphorylated water decreased significantly on average (Figures 4(a) and 4(b)).

3.4. HNF1 $\alpha$ Inhibits the STAT3 Pathway, Promotes Lipolytic Metabolism, and Inhibits Lipid Anabolism. To investigate the association between the HNF1 $\alpha$ and STAT3 signaling pathways, we examined the expression of $\operatorname{HNF} 1 \alpha$, SOCS3, and STAT3 and phosphorylation at $24 \mathrm{~h}$ and $48 \mathrm{~h}$. Western blot analysis showed that upregulation of $\mathrm{HNF} 1 \alpha$ expression promoted FCS-induced SOCS3 expression in LO2 cells and inhibited STAT3 phosphorylation, whereas downregulation of HNF1 $\alpha$ expression inhibited FFA-induced LOCS cell SOCS3 expression and promoted STAT3 phosphorylation (Figure 5(a)). 

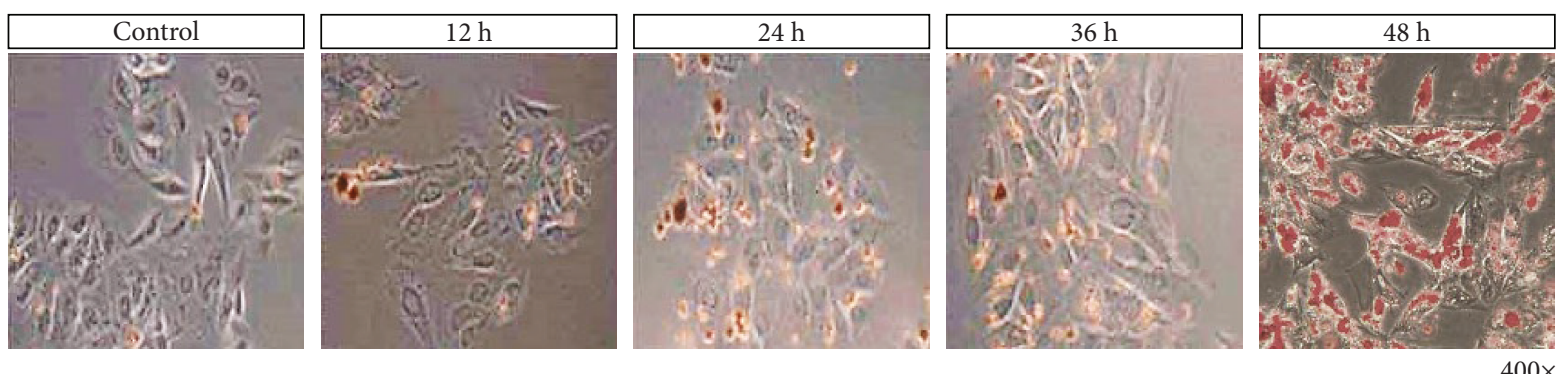

(a)
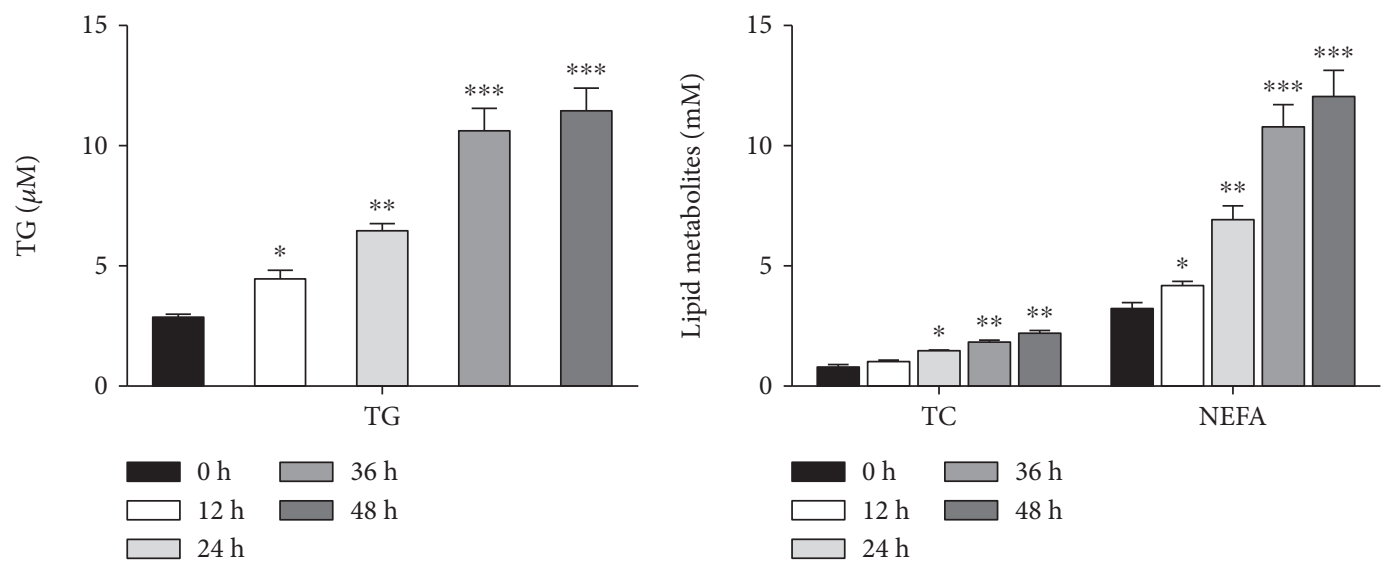

(b)

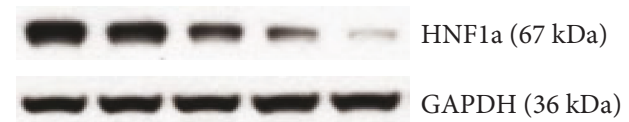

$0 \quad 12 \mathrm{~h} \quad 24 \mathrm{~h} \quad 36 \mathrm{~h} \quad 48 \mathrm{~h}$
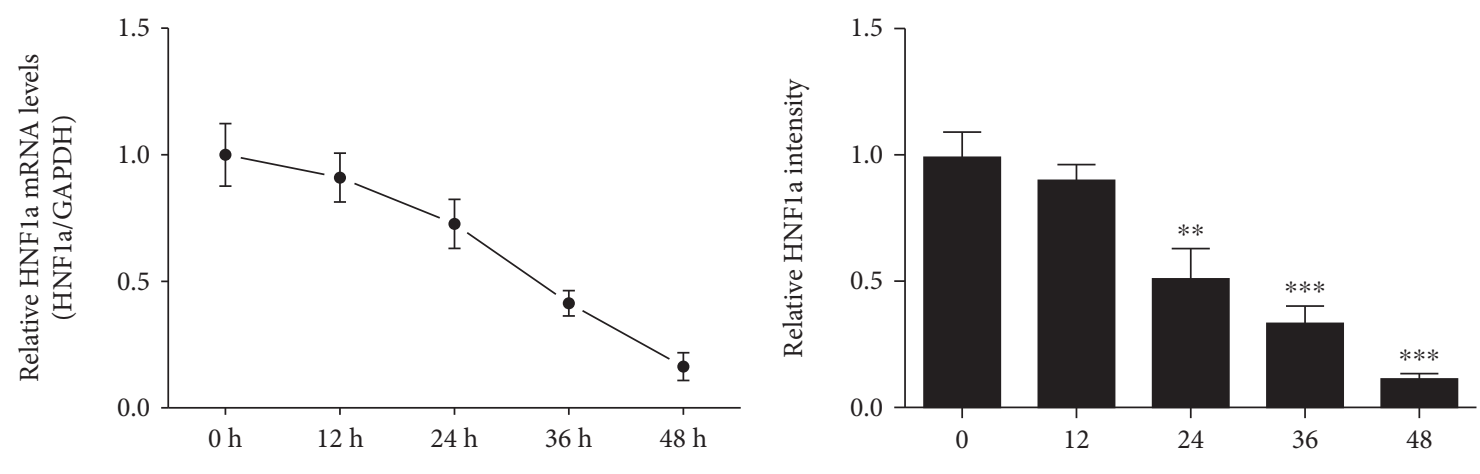

Hours

(c)

Figure 1: Continued. 

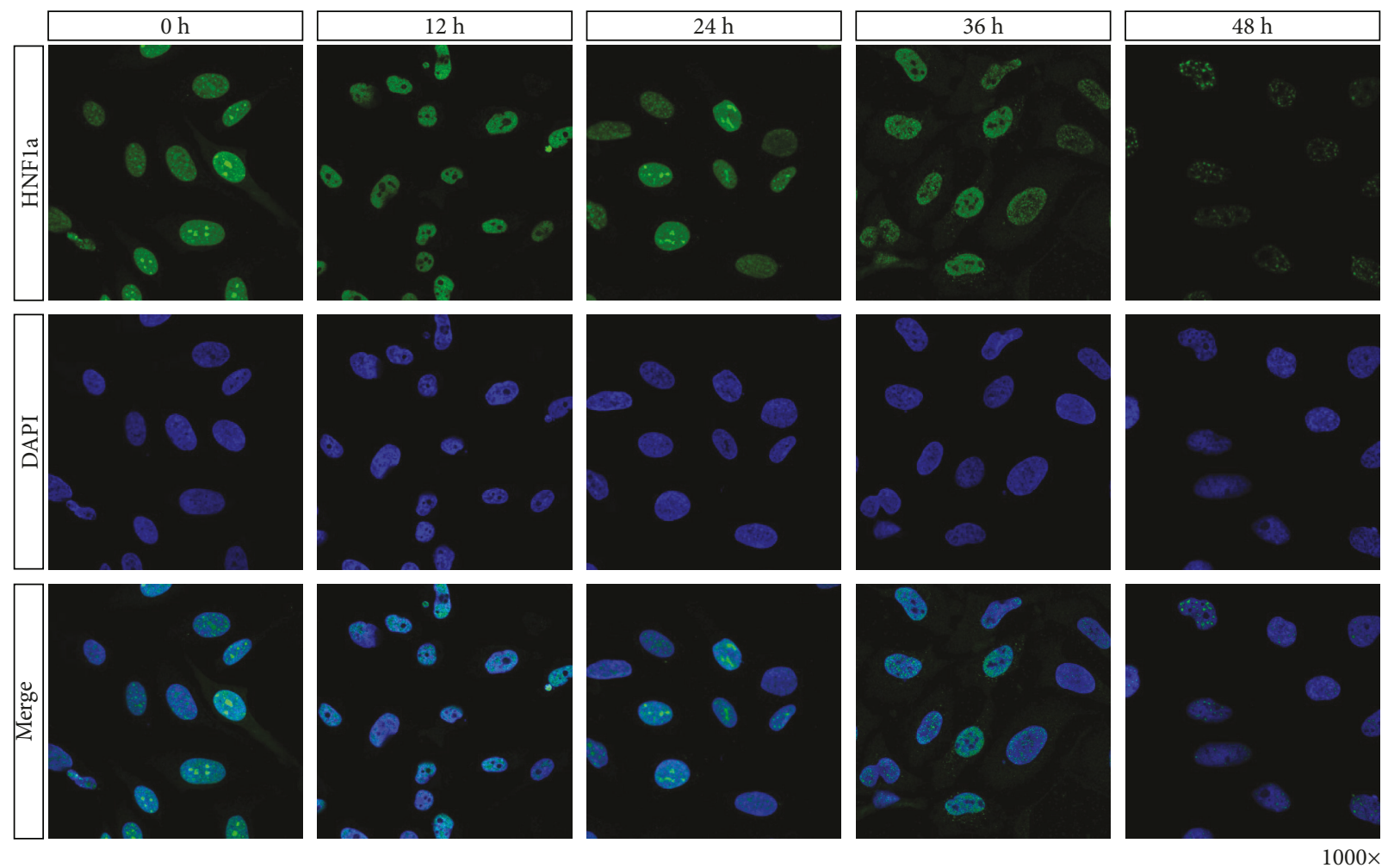

(d)

FIgURE 1: Decreased HNF1 $\alpha$ expression in FFA-induced fatty degeneration of LO2 cells. (a) Oil Red O staining showed that the number of lipid droplets in LO2 cells increased gradually with increased FFA induction time. (b) Biochemical indicators showed that with increasing FFA induction time, TC, TG, and NEFA content in the LO2 cells increased gradually. Reported values are the means + SD of the three independent tests, with ${ }^{*} p<0.05,{ }^{* *} p<0.01$, and ${ }^{* * *} p<0.001$. (c, d) RT-qPCR, western blot, and immunofluorescence staining showed that the expression of HNF1a mRNA and protein decreased with increasing FFA induction time.

In order to evaluate the effect of HNF $1 \alpha$ on lipid metabolism, we examined the expression of HNF1 $\alpha$ and mRNA and protein expression of SREBP-1c and PPAR $\alpha$ by RTqPCR and western blot at $24 \mathrm{~h}$ and $48 \mathrm{~h}$. Compared with the control group, the expression of SREBP-1c mRNA and protein in LOF cells decreased significantly with increasing expression of HNF1 $\alpha$ and the expression of PPAR $\alpha$ mRNA and protein increased significantly. With a decrease in HNF1 $\alpha$ expression, mRNA and protein levels of SREBP-1c in FFA-induced LO2 cells increased significantly and PPAR $\alpha$ mRNA and protein expression decreased significantly (Figure 5(b)).

3.5. STAT3 Inhibitor NSC74859 Can Reverse the Effect of the Downregulation of HNF1a Expression on Hepatic Lipid Metabolism. In the current study, we found that HNF1 $\alpha$ regulates the SOCS3-STAT3 signaling pathway. Together with previous studies, we hypothesized that the effect of HNF1 $\alpha$ on hepatic metabolism may be achieved through the SOCS3-STAT3 signaling pathway. To confirm this inference, NSC74859, the inhibitor of STAT3, was used.

The Oil Red O staining test showed that the addition of $100 \mathrm{nM}$ NSC74859 reduced the number of red granular lipid droplets in the FFA-induced $\mathrm{LO} 2$ cells and alleviated the steatosis of LO2 cells. Adding NSC74859 after the downregulation of HNF1 $\alpha$ expression reversed the increase in the number of red granular lipid droplets in LO2 cells induced by FFA downregulation of HNF $1 \alpha$ expression, aggravating the phenomenon of steatosis in LO2 cells (Figure 6(a)). The biochemical results showed that NSC74859 significantly decreased the levels of TG, TC, and NEFA in FFA-induced LO2 cells. The addition of NSC74859 also significantly reduced the levels of TG, TC, and NEFA that were elevated by downregulating the HNF1 $\alpha$ expression (Figure 6(b)). Western blot analysis showed that NSC74859 promoted phosphorylation of IRS-1 and AKT (Figures 6(c) and 6(d)). NSC74859 can somewhat alleviate the inhibition of IRS-1 and AKT phosphorylation caused by downregulating the HNF1 $\alpha$ expression. NSC74859 inhibits the expression of SREBP-1c and promotes the expression of PPAR $\alpha$. NSC7 4859 reversed the effects of downregulation of HNF1 $\alpha$ expression on SREBP-1c and PPAR $\alpha$ expression (Figure 6(e)).

3.6. HNF1 $\alpha$ Inhibits Steatosis through Suppressing STAT3 In Vivo. To confirm our results found in LO2 cells, we adopted an in vivo model using HNF1 $\alpha$ defect mice. Studies on HNF1 $\alpha$ using different knockout models have been reported before [23-25]. Herein, we show that after 8 weeks of HFD feeding, HNF1 $\alpha-/$ - mice had increased liver steatosis compared with WT group (Figure 7(a)). However, 

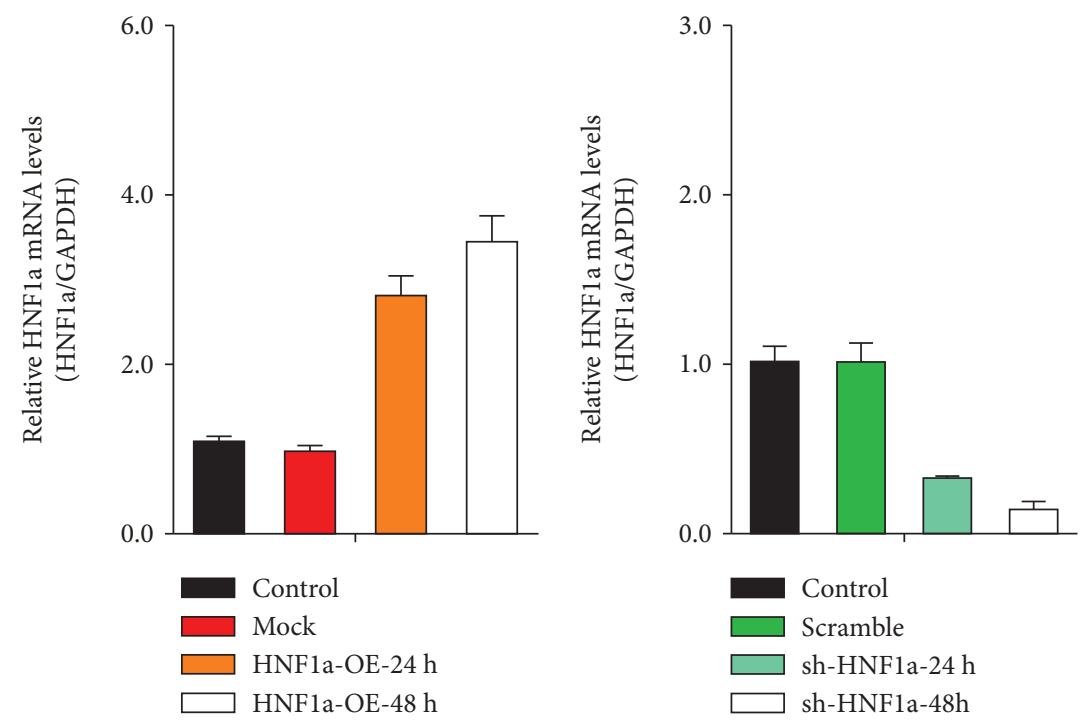

(a)
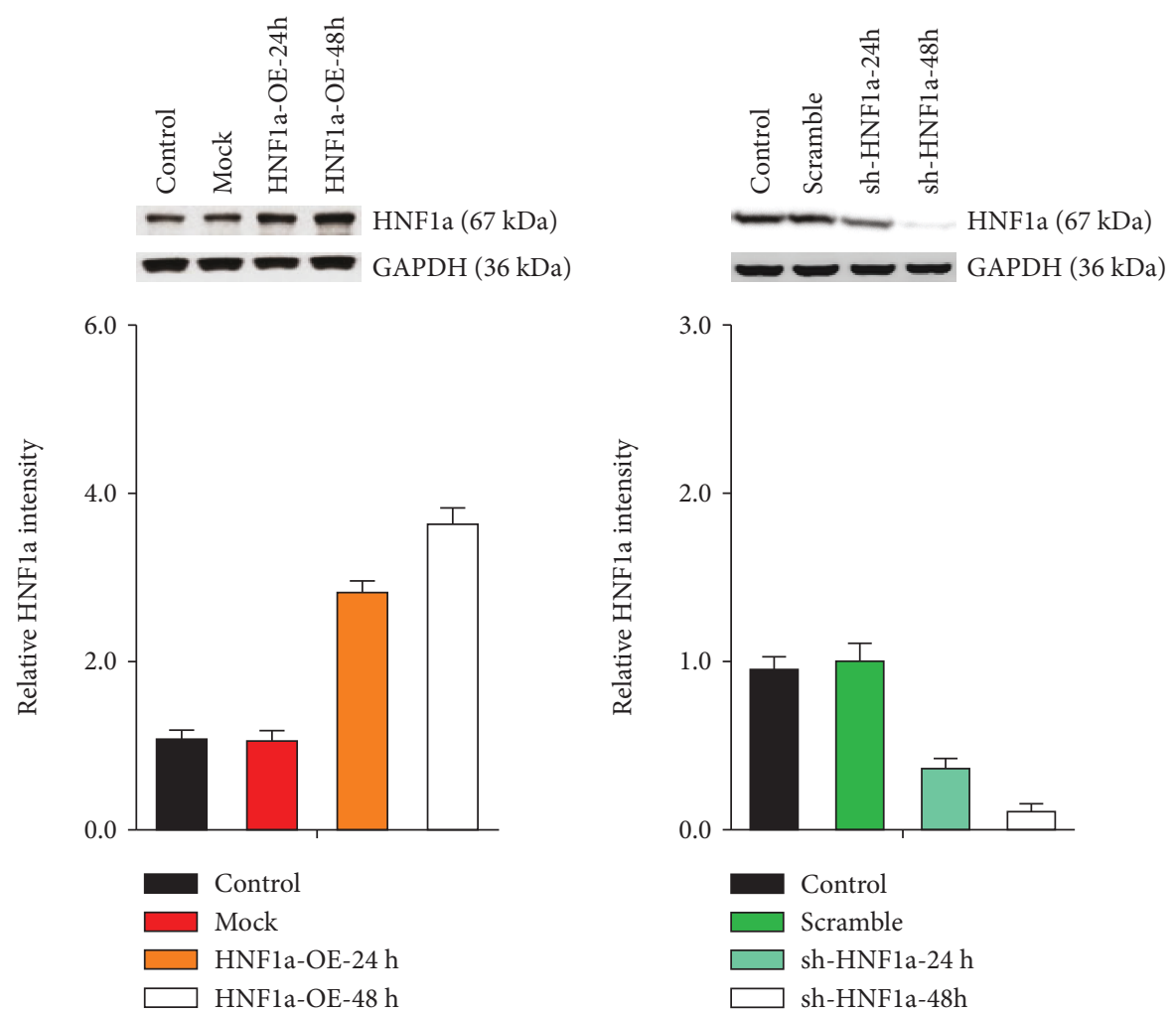

(b)

FIGURE 2: Efficiency assay for the HNF1 $\alpha$ overexpression and knockdown vector. (a) RT-qPCR showed that the gene expression of HNF1 $\alpha$ was effectively regulated in the overexpression and knockdown transgenic plants. (b) Western blot analysis showed that the HNF1 $\alpha$ protein was upregulated in the overexpression lines and downregulated in the knockdown lines.

in vivo treatment of HNF1 $\alpha$-/- mice with NSC 74859 significantly reduced liver steatosis. This data suggests that HNF1 $\alpha$ deficiency-induced liver steatosis is STAT3 dependent which is consistent with our results in LO2 cells as showed in Figure 6. Similarly, the liver sizes or weights were larger in HNF1 $\alpha$-/- mice while treating HNF1 $\alpha$-/- mice with NSC 74859 reduced both liver size and weight (Figure $7(b)$ ).
We also tested triglyceride, cholesterol, NEFA, fasting insulin, and HOMA-IR index; all these parameters were significantly higher in HNF1 $\alpha$-/- mice; and inhibition of STAT3 with NSC 74859 partially ameliorated these characters (Figures $7(\mathrm{c})-7(\mathrm{~g}))$. Western blot analysis first confirmed the expression of HNF1 $\alpha$ in liver tissue (Figure 7(h)). HNF $1 \alpha$ deficiency led to decreased expressions of SOCS3 and PPAR $\alpha$ 

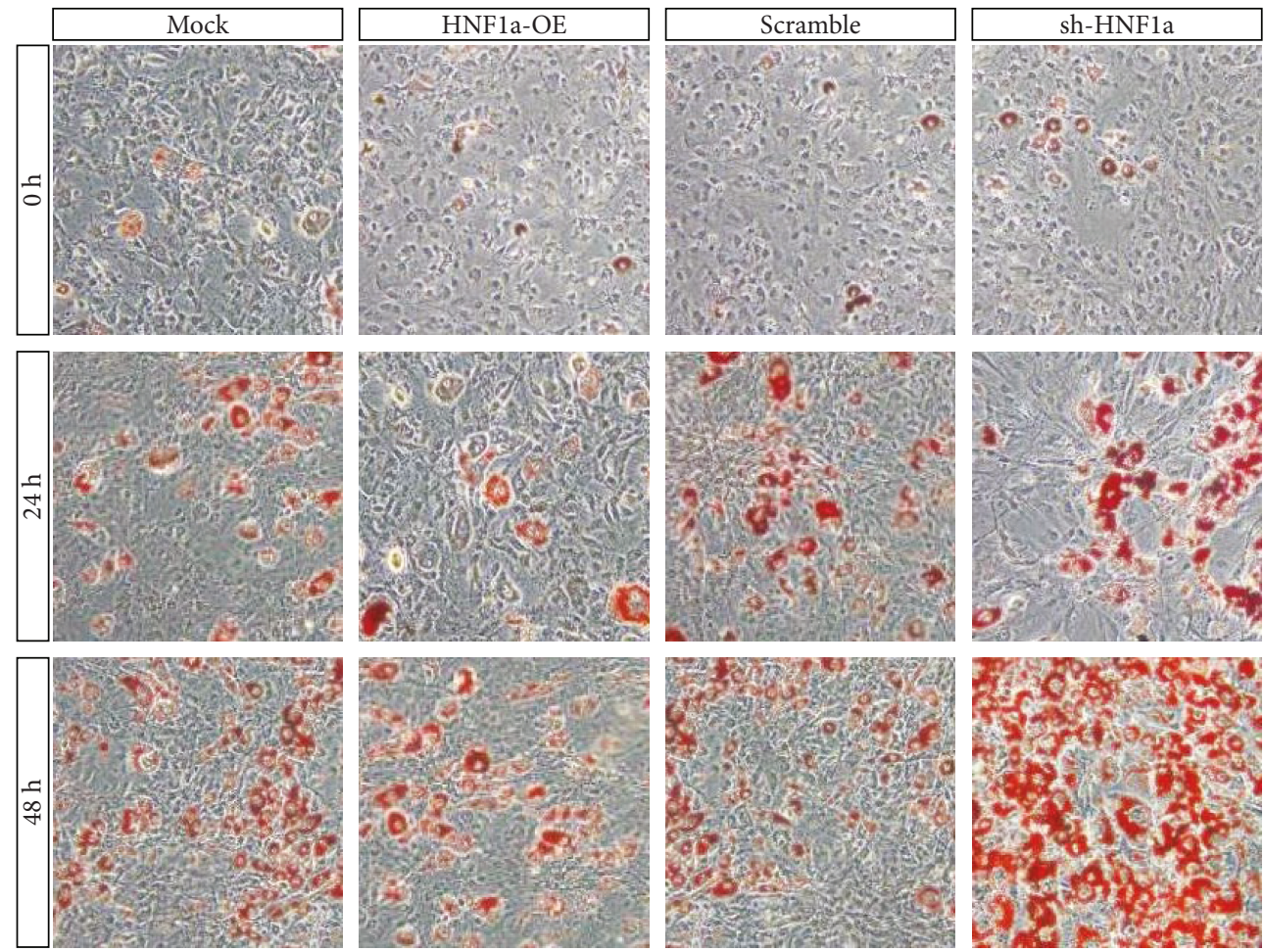

$200 \times$

(a)

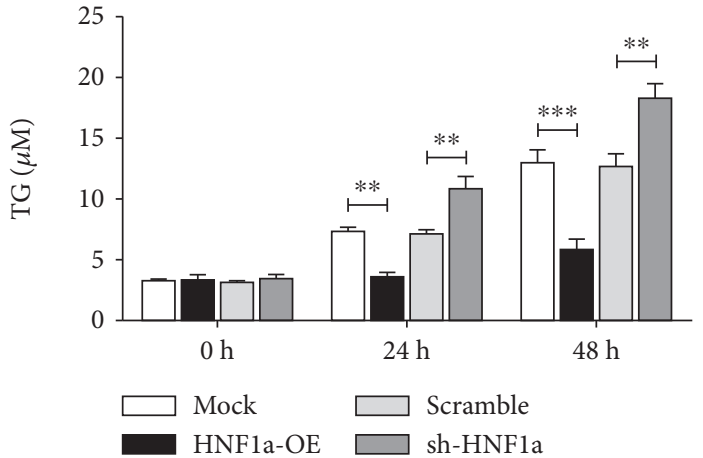

(b)

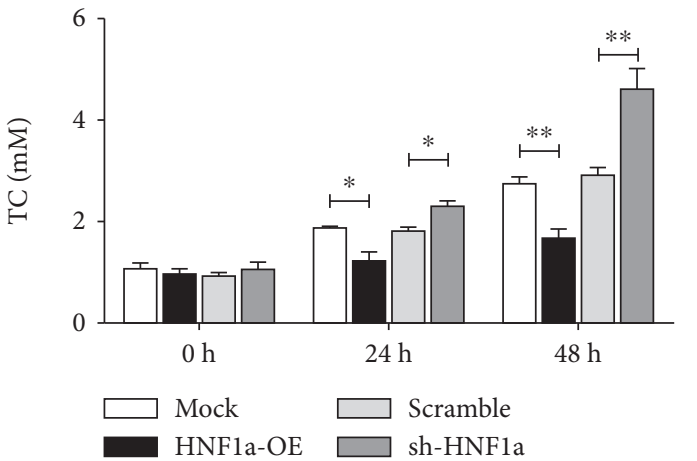

(c)

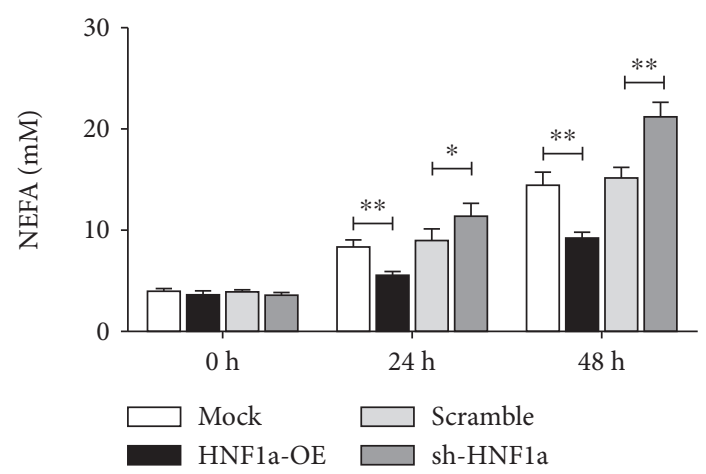

(d)

FIGURE 3: HNF1 $\alpha$ inhibits FFA-induced steatosis in LO2 cells. (a) Oil Red O staining showed that the number of red granular lipid droplets decreased after upregulating the expression of HNF1 $\alpha$ and the number of red granular lipid droplets increased after downregulating the expression of HNF1 $\alpha$. (b-d) Biochemical indicator tests showed that the upregulation of HNF1 $\alpha$ expression caused significant decreases in TC, TG, and NEFA content. Downregulation of HNF1 $\alpha$ expression led to significantly increased content of TC, TG, and NEFA. Reported values are the means $+\mathrm{SD}$ of the three independent tests, with ${ }^{*} p<0.05,{ }^{* *} p<0.01$, and ${ }^{* * *} p<0.001$. 


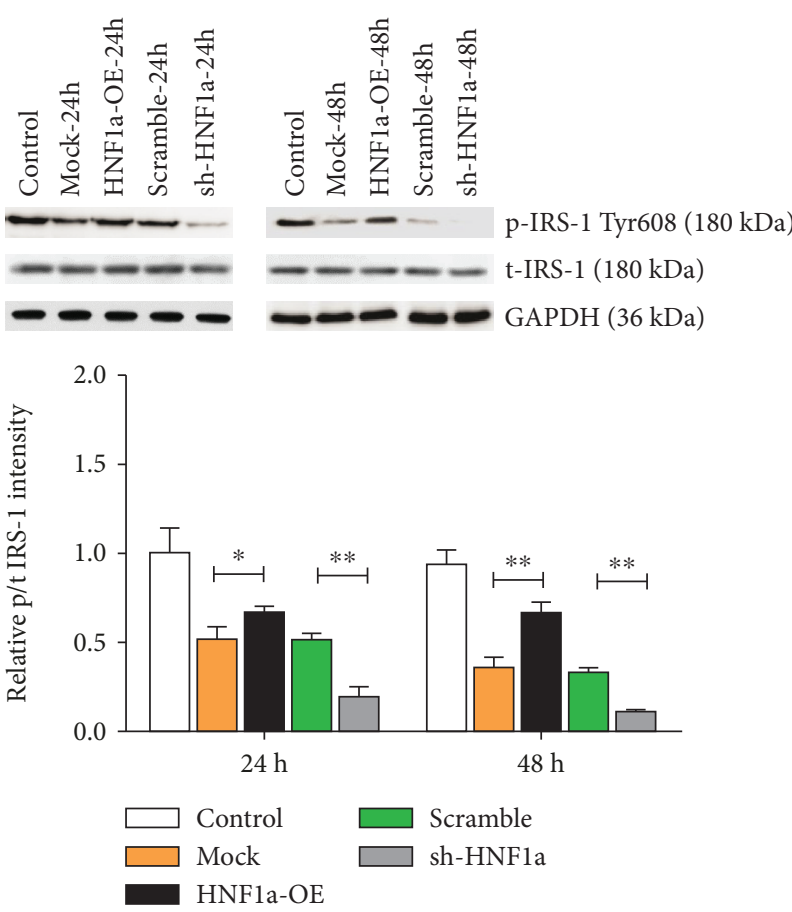

(a)
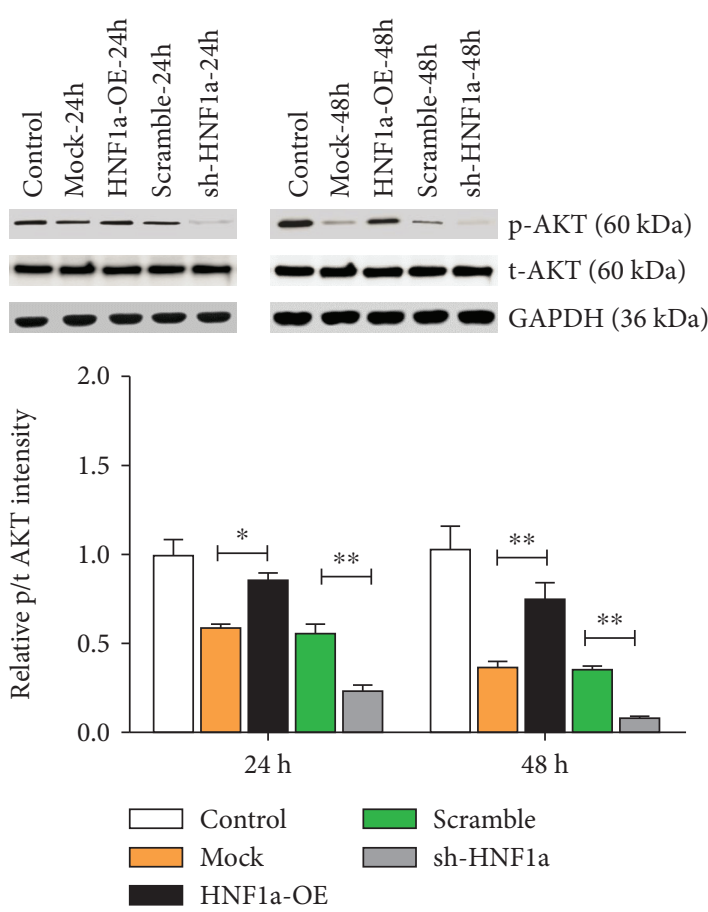

(b)

FIgURE 4: HNF1 $\alpha$ promotes activation of the islet signaling pathway. $(\mathrm{a}, \mathrm{b})$ Western blot analysis showed that upregulation of HNF1 $\alpha$ expression promoted IRS-1 and AKT phosphorylation and downregulation of HNF1 $\alpha$ expression inhibited IRS-1 and AKT phosphorylation. Reported values are the means + SD of the three independent tests, with ${ }^{*} p<0.05,{ }^{* *} p<0.01$, and ${ }^{* * *} p<0.001$.

and phosphorylation of AKT and IRS-1 while phosphorylation of STAT3 and expression of SREBP-1c were increased in HNF1 $\alpha-/$ - mouse liver cells (Figure $7(\mathrm{~h})$ ). Interestingly, in vivo treatment of HNF1 $\alpha$-/- mice with NSC74859 slightly increased phosphorylation of IRS-1 and AKT compared with HNF1 $\alpha-/$ - mice (Figure $7(\mathrm{~h})$ ). We also showed that NS C74859 inhibited the expression of SREBP-1c and promoted the expression of PPAR $\alpha$. NSC74859 reversed the effects of deficiency of HNF $1 \alpha$ expression on SREBP-1c and PPAR $\alpha$ expression (Figure $7(\mathrm{~h})$ ). These data further confirm that HNF1 $\alpha$ regulates hepatic lipid metabolism by promoting the expression of SOCS-3 and negatively regulating the STAT3 signaling pathway.

\section{Discussion}

Here, we evaluated the effect and clarified the regulation and mechanism of HNF1 $\alpha$ on hepatic glycolipid metabolism. Our results showed that FFA-induced hepatocyte LO2 steatosis inhibited the expression of HNF1 $\alpha$. NAFLD, which is characterized by excessive deposition of hepatic fat, is extremely harmful, but its developmental mechanism is still unclear. Our results suggested that the development of NAFLD may be related to the excessive deposition of hepatocyte fat together with inhibition of HNF1 $\alpha$ and other genes essential for maintaining normal liver function. The inhibition of HNF $1 \alpha$ on FFA-induced hepatic LO2 steatosis also demonstrated that HNF1 $\alpha$ is involved in the regulation of hepatic fat metabolism and has the effect of preventing excessive deposition of hepatic fat. SREBP-1c is an important transcription factor that regulates the de novo synthesis and glycolysis pathways of fat. SREBP-1c regulates fatty acid synthase and can cause lipid deposition, which plays an important role in the pathogenesis of NAFLD [26]. PPAR $\alpha$ is a transcription factor of the nuclear hormone receptor superfamily. Its main function in the liver is as a lipid sensor, recognizing fatty acids flowing into the liver and regulating the expression of specific genes affecting lipid metabolism [27]. PPAR $\alpha$ plays an important role in the oxidative decomposition of fat and has a protective effect on NAFLD [28, 29]. We found that HNF1 $\alpha$ inhibits the expression of SREBP-1c and promotes the expression of PPAR $\alpha$. This result further indicates that HNF $1 \alpha$ is involved in the regulation of hepatic lipid metabolism. HNF $4 \alpha$ has been reported to play a key role in controlling hepatic CES2 expression in diabetes, obesity, or NASH [30]; thus, we also investigated and found that HNF1 $\alpha$ positively regulates CES2 expression though much need to be done in the future (data not shown). Mouse experiments have also confirmed that liver-specific knockdown of the HNF1 $\alpha$ gene leads to increased fatty acid synthesis in the liver and excessive deposition of fat in the liver [31].

Genome-wide association analysis (GWAS) results revealed a correlation between the HNF1 $\alpha$ mutations and the potential risk of developing type 2 diabetes [32]. Insulin resistance is the crucial initiating factor in the development of metabolic diseases such as NAFLD and diabetes. To achieve its function, insulin must first bind to the insulin receptor on the cell surface and phosphorylate to activate 

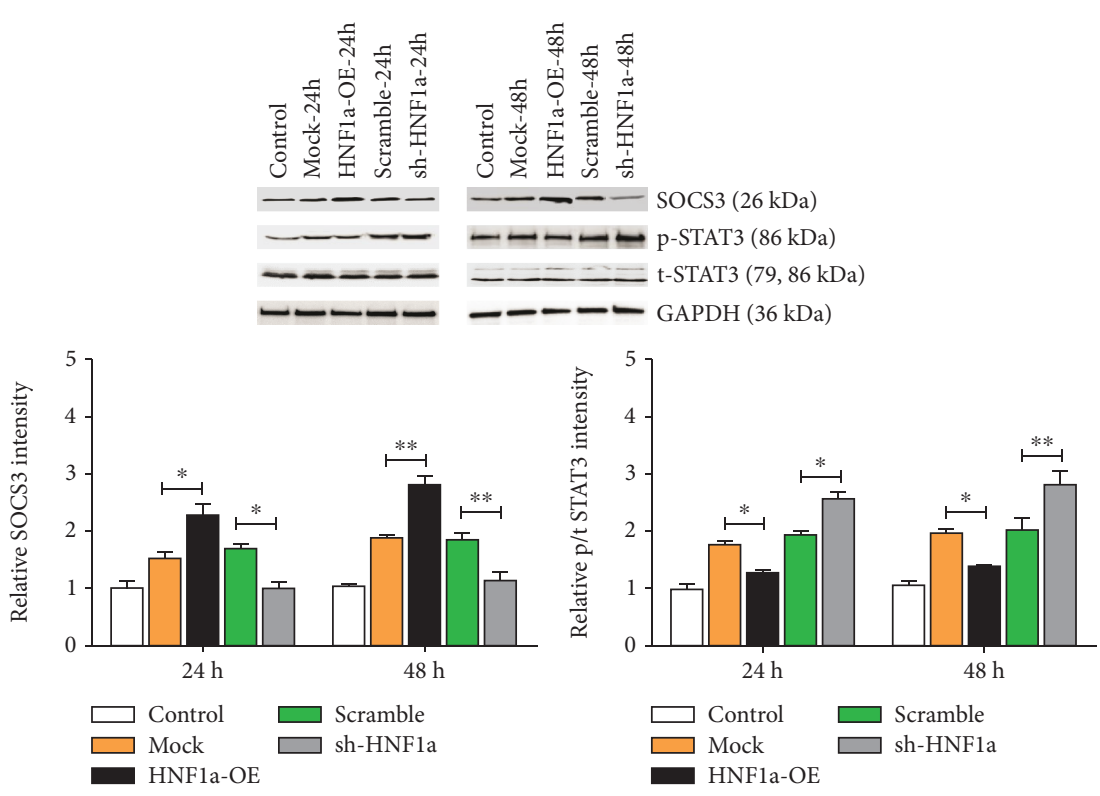

(a)
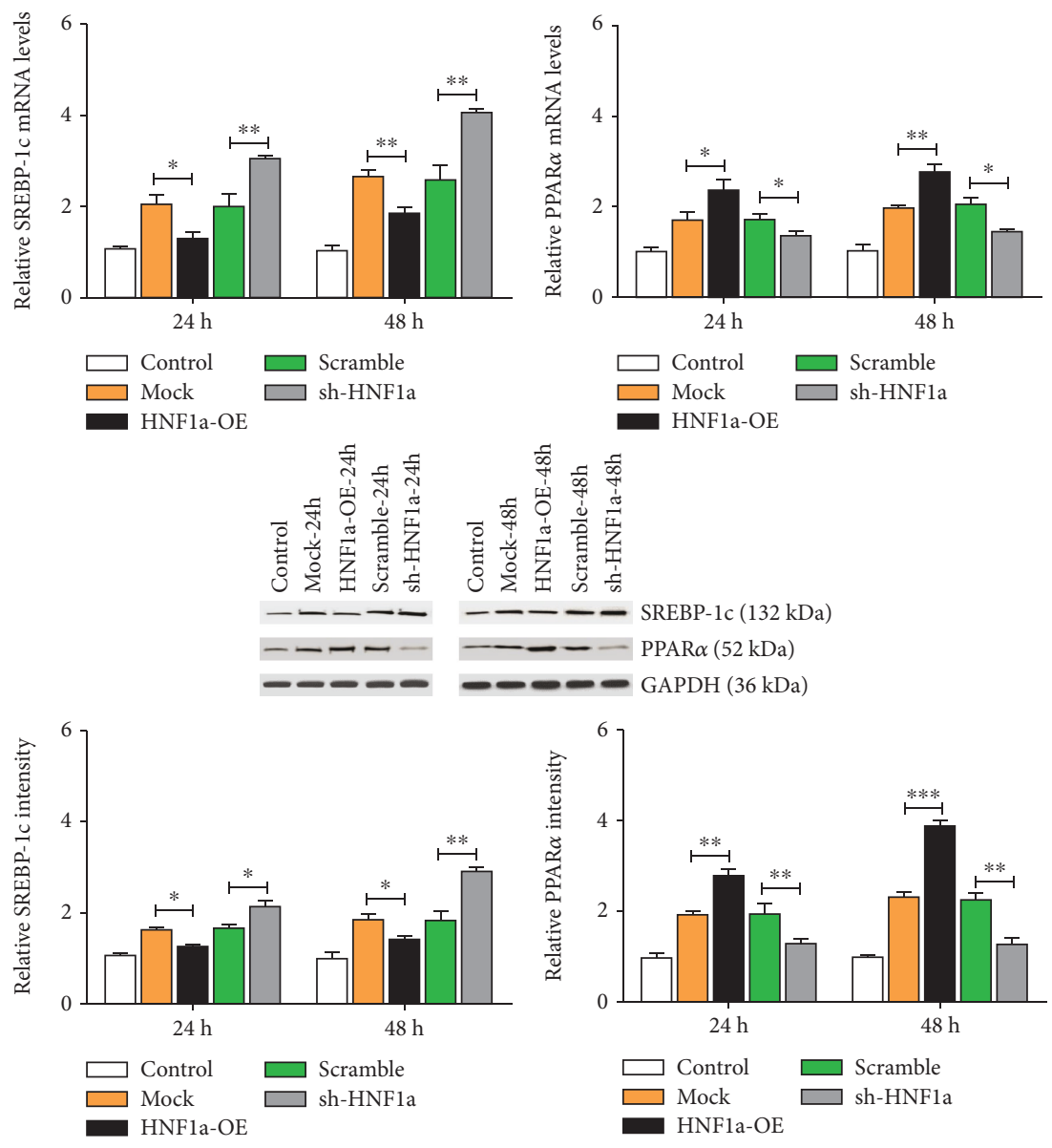

(b)

FIGURE 5: HNF1 $\alpha$ inhibits the STAT3 pathway and promotes lipolytic catabolism lipid anabolism. (a) Western blot analysis showed that upregulation of HNF1 $\alpha$ expression promoted the expression of SOCS-3, inhibited the phosphorylation of STAT3, downregulated the expression of HNF1 $\alpha$, inhibited the expression of SOCS-3, and promoted the phosphorylation of STAT3. (b) RT-qPCR and western blot showed that upregulation of HNF1 $\alpha$ expression inhibited the expression of SREBP-1c, promoted the expression of PPAR $\alpha$, downregulated the expression of HNF1 $\alpha$, promoted the expression of SREBP-1c, and inhibited the expression of PPAR $\alpha$. Reported values are the means $+\mathrm{SD}$ of the three independent tests, with ${ }^{*} p<0.05,{ }^{* *} p<0.01$, and ${ }^{* * *} p<0.001$. 

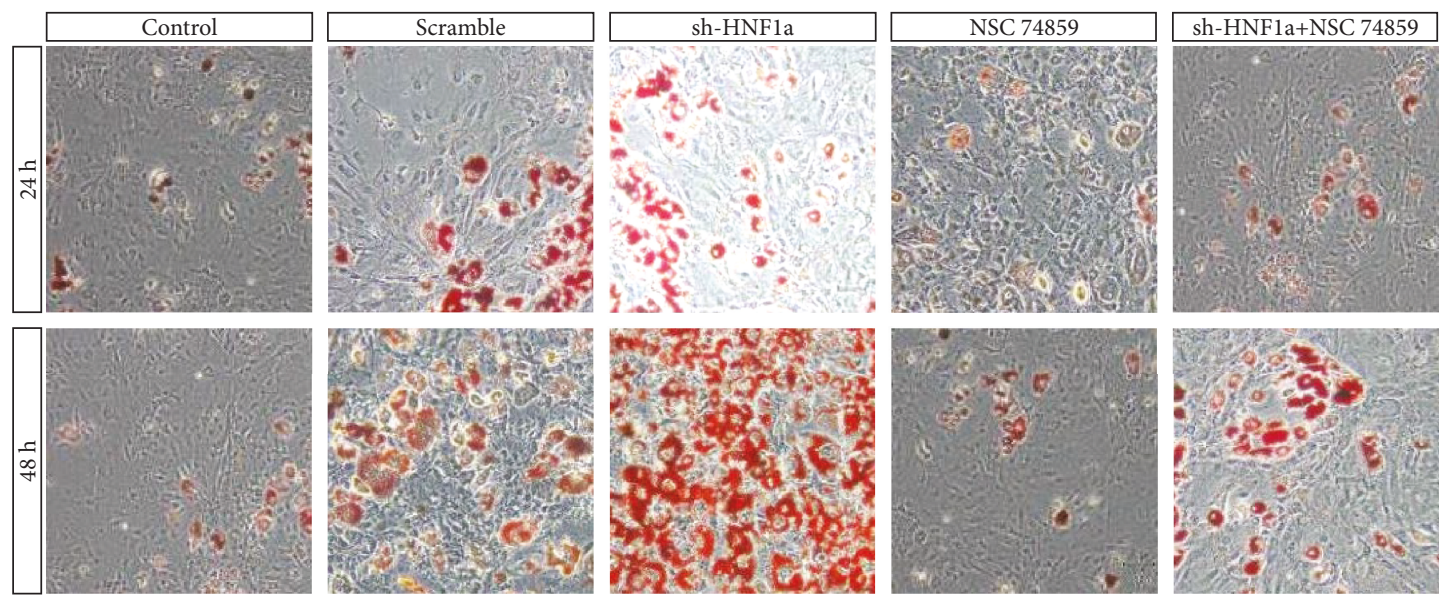

(a)
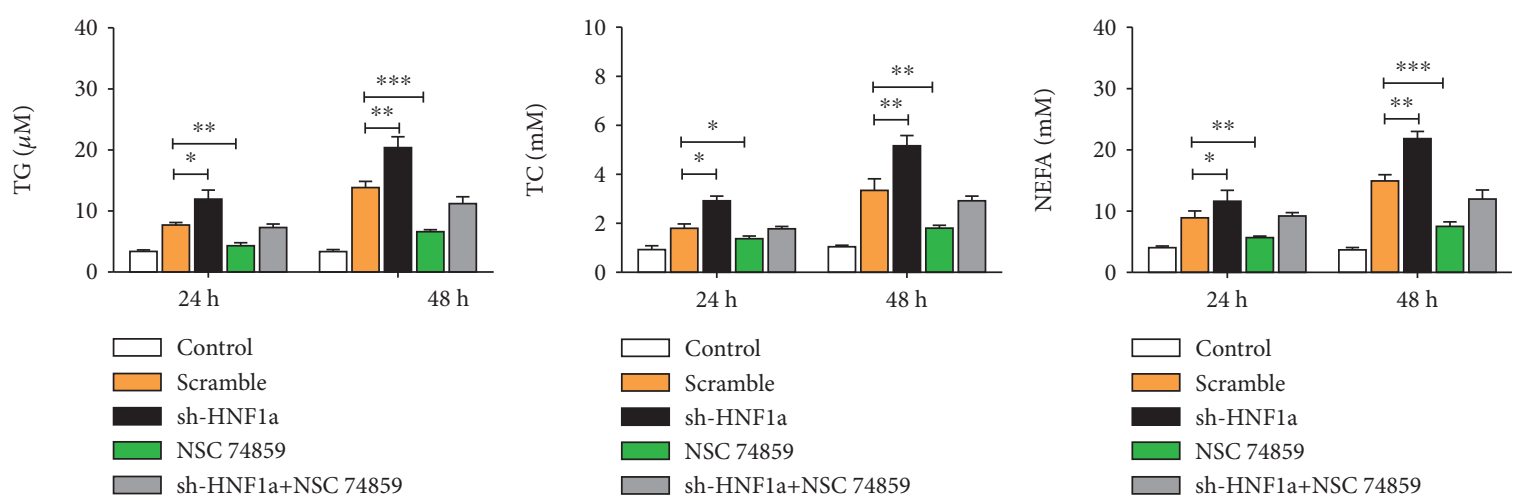

(b)
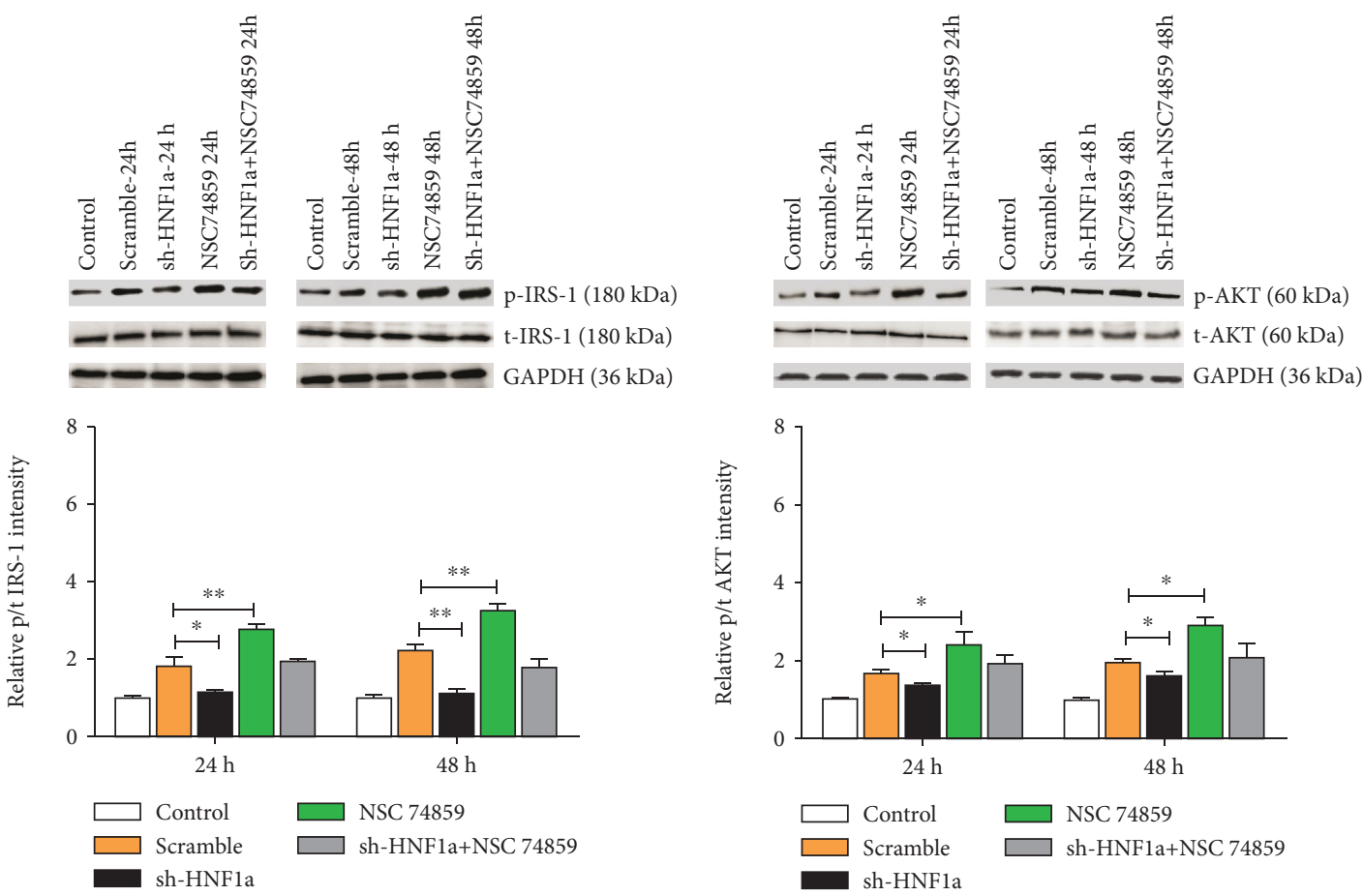

(c)

(d)

FIgURe 6: Continued. 


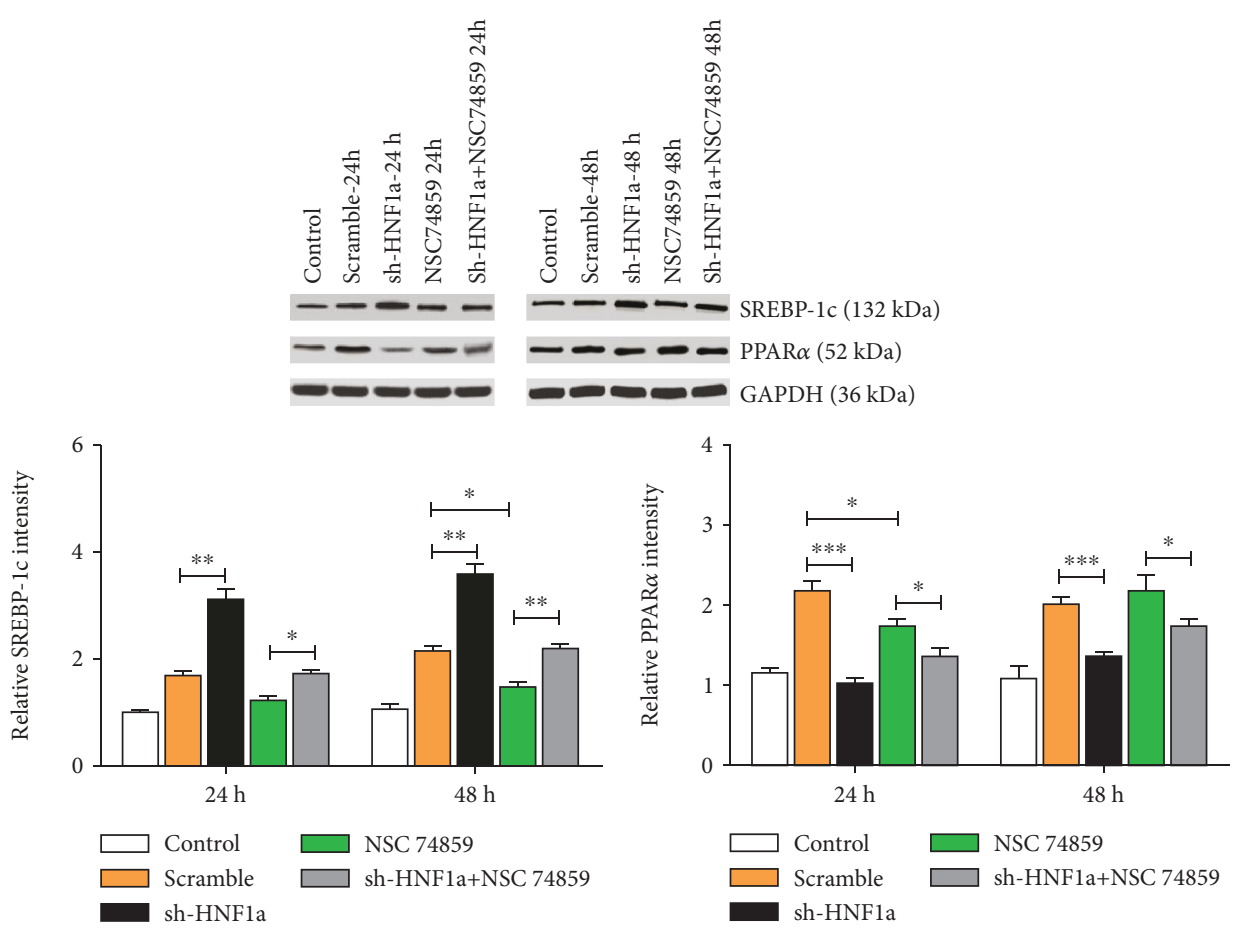

(e)

FIGURE 6: STAT3 inhibitor NSC74859 can reverse the effect of the downregulation of HNF1 $\alpha$ expression on hepatic glycolipid metabolism. (a) Oil Red O staining test showed that NSC74859 reduced the number of red granular lipid droplets in LO2 cells induced by FFA. Downregulation of HNF1 $\alpha$ expression followed by addition of NSC74859 reduced FAR-induced red granule lipid droplets in LO2 cells. (b) Biochemical indicators showed that NSC74859 reduced TC, TG, and NEFA contents. After downregulating the HNF1 $\alpha$ expression and adding NSC74859, the contents of TC, TG, and NEFA decreased significantly. (c, d) Western blot analysis showed that NSC74859 promoted IRS-1 and AKT phosphorylation. Downregulation of HNF1 $\alpha$ expression followed by addition of NSC74859 abolished the inhibition of IRS-1 and AKT phosphorylation by downregulating the HNF1 $\alpha$ expression. (e) Western blot analysis showed that NSC74859 inhibited the expression of SREBP-1c and promoted the expression of PPAR $\alpha$. Downregulation of HNF1 $\alpha$ expression followed by NSC74859 reversed the effects of downregulation of HNF1 $\alpha$ expression on SREBP-1c and PPAR $\alpha$ expression. Reported values are the means $+\mathrm{SD}$ of the three independent tests, with ${ }^{*} p<0.05,{ }^{* *} p<0.01$, and ${ }^{* * *} p<0.001$.

IRS. The activated IRS continues to activate PI3K/AKT, which regulates glucose transport and glycogen synthesis. Our results show that HNF1 $\alpha$ promotes phosphorylation with IRS-1 and AKT, i.e., HNF1 $\alpha$ promotes activation of the insulin signaling pathway. The regulation of lipid metabolism by HNF $1 \alpha$ is a potential cause of its close association with the development of metabolic diseases such as NAFLD and type 2 diabetes.

Previous studies have shown that inhibition of liver HNF $1 \alpha$ not only increases lipid synthesis and excessive fat deposition but also promotes phosphorylation of STAT3 $[31,33]$. Our results also confirmed that $\mathrm{HNF} 1 \alpha$ promotes the expression of SOCS3, which is a STAT3 signaling pathway negative feedback regulator, and inhibits STAT3 phosphorylation. That is, HNF1 $\alpha$ inhibits the activation of the STAT3 signaling pathway by promoting the expression of SOCS3. Mouse experiments have shown that liver-specific knockdown of STAT3 increases hepatic glucose production [34]. In insulin-resistant diabetic mice, overexpression of STAT3 not only increases plasma triglyceride and total cholesterol levels but also promotes transcription of lipid synthesis-related enzymes such as fatty acid synthase and acetyl-CoA carboxylase [35]. This indicated that STAT3 was involved in the regulation of hepatic glycolipid metabolism and in maintenance of hepatic glycolipid homeostasis.

Our results indicated that HNF1 $\alpha$ inhibits lipid anabolism, promotes lipolysis, and promotes the activation of the insulin signaling pathway. There is a close relationship between hepatic glucose metabolism and lipid metabolism, which share many common regulatory elements and metabolites. Combined with previous studies, we concluded that HNF1 $\alpha$ achieved the above metabolic regulation through the STAT3 signaling pathway. To further confirm our inference, we used the STAT3 inhibitor NSC74859 after downregulating the HNF $1 \alpha$ expression. The results showed that the STAT3 inhibitor NSC74859 can reverse the effect of HNF1 $\alpha$ on glucose and lipid metabolism, supporting our inference.

\section{Conclusions}

In summary, HNF $1 \alpha$ promotes the activation of insulin signaling pathways, encourages fat decomposition, and inhibits 
WT+chow

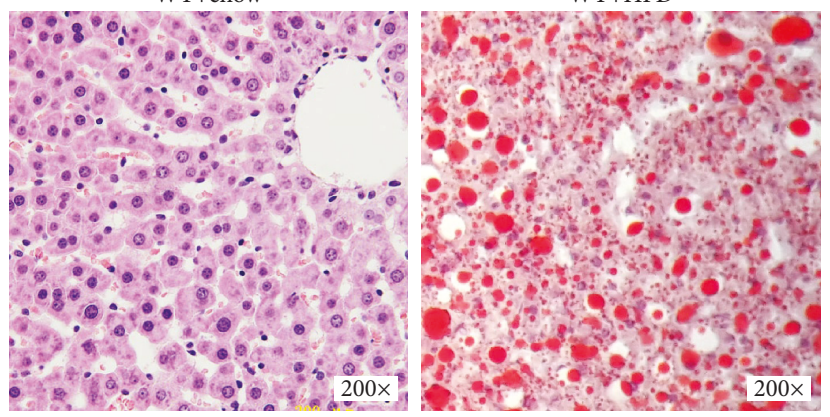

HNF1a-/-+HFD

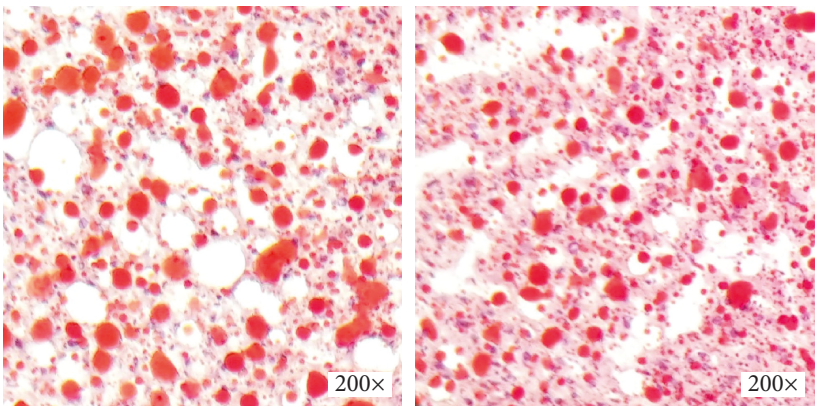

(a)

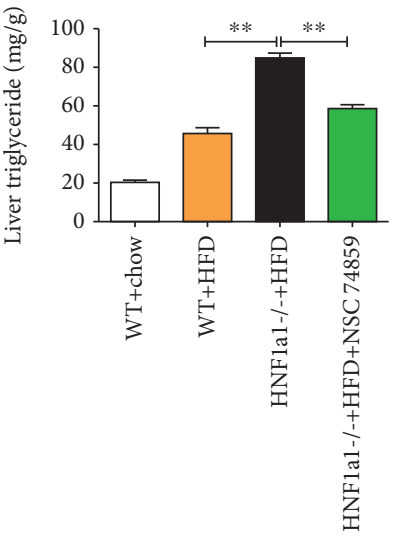

(c)

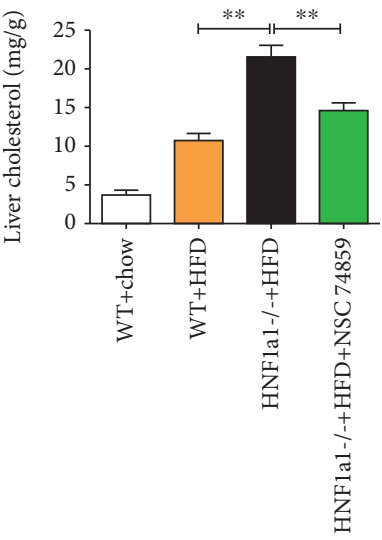

(d)

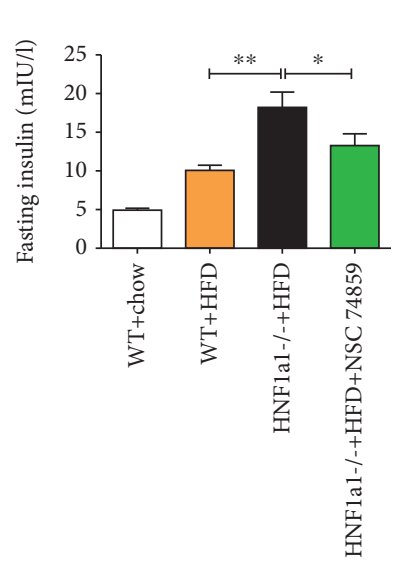

(f)

(g)
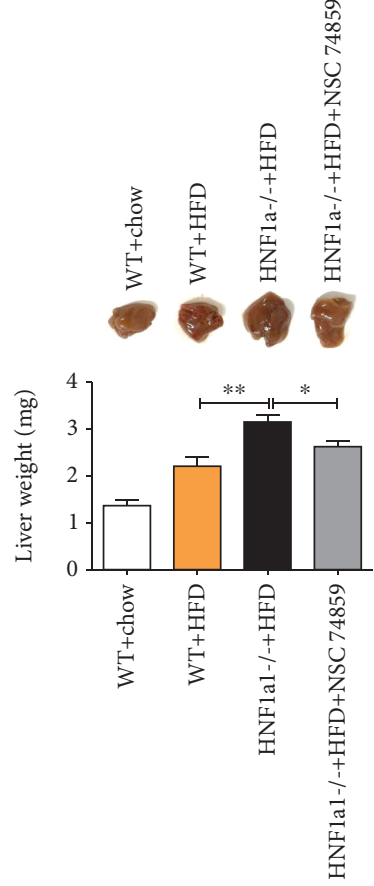

(b)

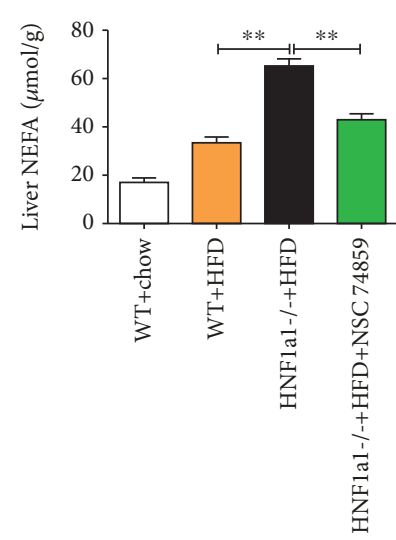

(e)

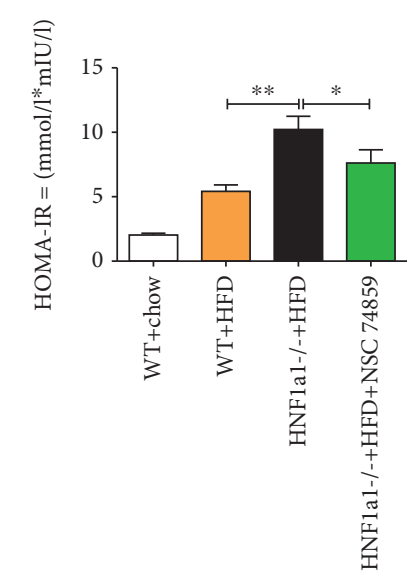

Figure 7: Continued. 


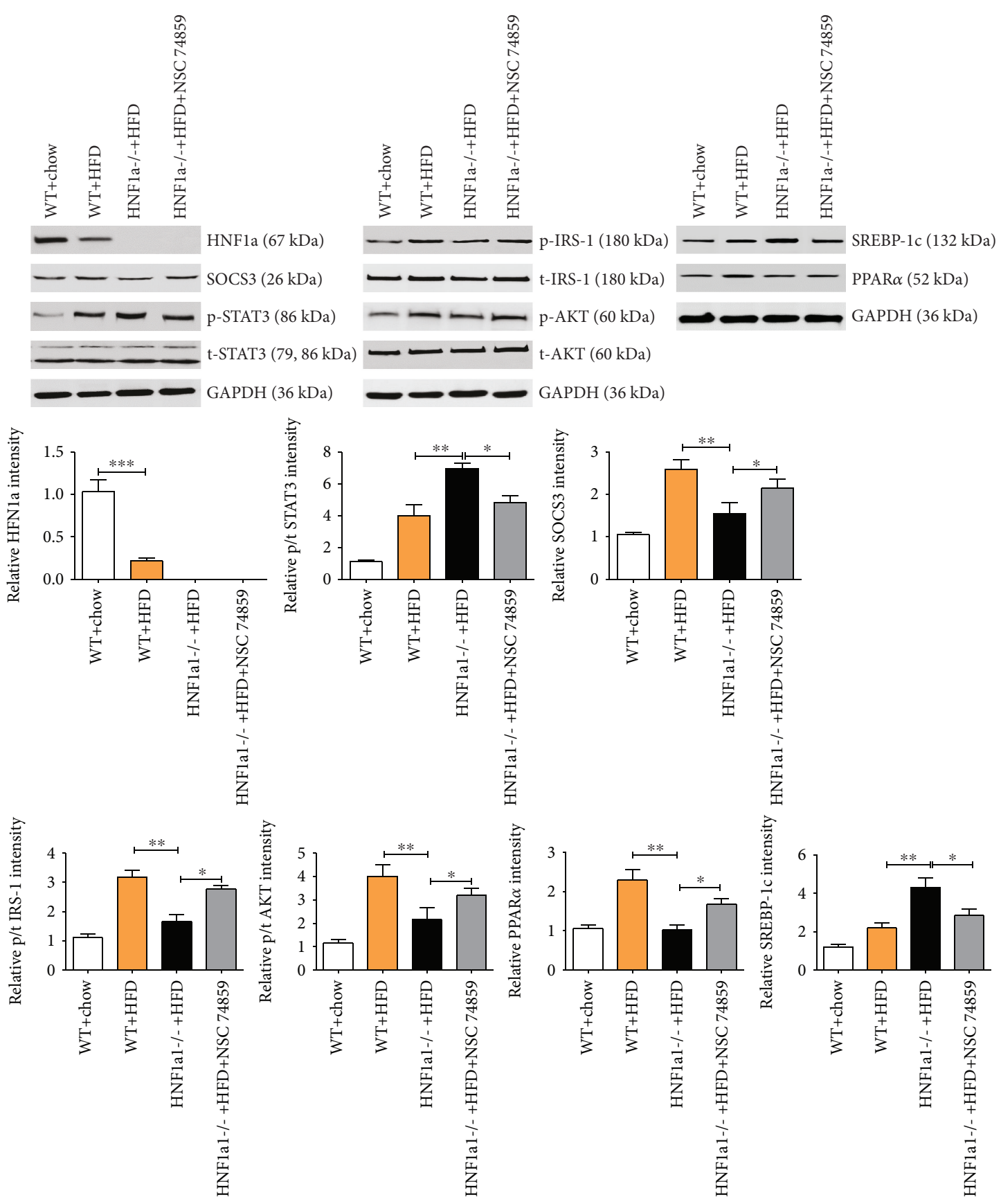

(h)

FIgURE 7: HNF1 $\alpha$ inhibits steatosis through suppressing STAT3 in vivo. (a) Oil Red O staining showed that increased liver steatosis in HNF1 $\alpha-/$ - mouse liver compared with WT HFD group. Treatment of NSC74859 in HNF1 $\alpha$-/- mice rescued them from severe steatosis. (b) Liver weight of HNF1 $\alpha-/$ - mice were significantly higher than WT mice fed with HFD, treatment of NSC74859 decreased mouse liver weight. (c-e) Biochemical indicators showed that HNF1 $\alpha$ deficiency increased triglyceride (TG), cholesterol (TC), and nonesterified fatty acid (NEFA) contents from the liver tissue. After treating the mice with NSC74859, the contents of TG, TC, and NEFA decreased significantly. (f, g) Serum fasting insulin levels were determined by ELISA, and homeostasis model assessment of insulin resistance (HOMA-IR) index was calculated as $[\mathrm{FBG}(\mathrm{mmol} / \mathrm{l}) \times \mathrm{FIns}(\mathrm{mIU} / \mathrm{l})] / 22.5$. $n=4-8$ per group, at the 8 th week. HNF1 $\alpha$ defect mice were significantly higher than WT mice fed with HFD. After treating the mice with NSC74859, the insulin levels and the HOMA-IR index decreased significantly. (h) Western blot analysis showed that HNF1 $\alpha$ deficiency increased the expression of SREBP-1c and phosphorylation of STAT3 and reduced the expressions of SOCS3 and PPAR $\alpha$ and phosphorylation of IRS-1 and AKT. Treating HNF1 $\alpha$ defect mice with NSC74859 reversed these protein expressions: NSC74859 inhibited the expression of SREBP-1c and promoted the expression of PPAR $\alpha$. All values are expressed as mean \pm SEM, $n=8-12$ per group, ${ }^{*} p<0.05,{ }^{* *} p<0.01$, and ${ }^{* * *} p<0.001$. 
the metabolic regulation of lipid synthesis via negatively regulating the STAT3 signaling pathways. This result indicates that $\mathrm{HNF} 1 \alpha$ is likely to prevent excessive deposition of hepatocyte fat by negatively regulating the STAT3 signaling pathway, thus forming a protective effect on NAFLD. This provides an effective strategy for the treatment of NAFLD, insulin resistance, and type 2 diabetes.

\section{Data Availability}

The data used to support the findings of this study are available from the corresponding author upon reasonable request.

\section{Conflicts of Interest}

The authors declare that there is no conflict of interest regarding the publication of this paper.

\section{Acknowledgments}

This study is supported by the general program from the Foundation of Shanghai Municipal Commission of Health and Family Planning (20124283), China, and Jiangsu University 2018 Clinical Medical Science and Technology Development Fund Project.

\section{References}

[1] M. V. Machado and H. Cortez-Pinto, "Non-alcoholic fatty liver disease: what the clinician needs to know," World Journal of Gastroenterology, vol. 20, no. 36, pp. 12956-12980, 2014.

[2] E. M. Brunt, C. G. Janney, A. M. Bisceglie, B. A. Neuschwander-Tetri, and B. R. Bacon, "Nonalcoholic steatohepatitis: a proposal for grading and staging the histological lesions," The American Journal of Gastroenterology, vol. 94, no. 9, pp. 2467-2474, 1999.

[3] P. Bedossa, C. Poitou, N. Veyrie et al., "Histopathological algorithm and scoring system for evaluation of liver lesions in morbidly obese patients," Hepatology, vol. 56, no. 5, pp. 17511759, 2012.

[4] D. E. Kleiner, E. M. Brunt, M. van Natta et al., "Design and validation of a histological scoring system for nonalcoholic fatty liver disease," Hepatology, vol. 41, no. 6, pp. 1313-1321, 2005.

[5] N. Alkhouri, R. de Vito, A. Alisi et al., "Development and validation of a new histological score for pediatric nonalcoholic fatty liver disease," Journal of Hepatology, vol. 57, no. 6, pp. 1312-1318, 2012.

[6] J. Shen, H. L. Y. Chan, G. L. H. Wong et al., "Non-invasive diagnosis of non-alcoholic steatohepatitis by combined serum biomarkers," Journal of Hepatology, vol. 56, no. 6, pp. 13631370, 2012.

[7] L. A. Adams, J. F. Lymp, J. St. Sauver et al., “The natural history of nonalcoholic fatty liver disease: a population-based cohort study," Gastroenterology, vol. 129, no. 1, pp. 113-121, 2005.

[8] M. Ekstedt, L. E. Franzén, U. L. Mathiesen et al., "Long-term follow-up of patients with NAFLD and elevated liver enzymes," Hepatology, vol. 44, no. 4, pp. 865-873, 2006.

[9] M. Kosmidou and H. Milionis, "Diabetes mellitus and nonalcoholic fatty liver disease: the thread of Ariadne," Minerva Endocrinologica, vol. 42, no. 2, pp. 109-121, 2017.
[10] N. C. Leite, C. A. Villela-Nogueira, C. R. Cardoso, and G. F. Salles, "Non-alcoholic fatty liver disease and diabetes: from physiopathological interplay to diagnosis and treatment," World Journal of Gastroenterology, vol. 20, no. 26, pp. 83778392, 2014.

[11] Z. M. Younossi, A. B. Koenig, D. Abdelatif, Y. Fazel, L. Henry, and M. Wymer, "Global epidemiology of nonalcoholic fatty liver disease-meta-analytic assessment of prevalence, incidence, and outcomes," Hepatology, vol. 64, no. 1, pp. 73-84, 2016.

[12] L. Pelletier, S. Rebouissou, D. Vignjevic, P. Bioulac-Sage, and J. Zucman-Rossi, "HNF1 $\alpha$ inhibition triggers epithelialmesenchymal transition in human liver cancer cell lines," BMC Cancer, vol. 11, no. 1, p. 427, 2011.

[13] A. K. Ovsyannikova, O. D. Rymar, D. E. Ivanoshchuk et al., "A Case of Maturity Onset Diabetes of the Young (MODY3) in a Family with a Novel HNF1A Gene Mutation in Five Generations," Diabetes Therapy, vol. 9, no. 1, pp. 413-420, 2018.

[14] M. St-Jean, F. Boudreau, A. C. Carpentier, and M. F. Hivert, "HNF1 $\alpha$ defect influences post-prandial lipid regulation," PLoS One, vol. 12, no. 5, article e0177110, 2017.

[15] E. Ekholm, R. Nilsson, L. Groop, and C. Pramfalk, “Alterations in bile acid synthesis in carriers of hepatocyte nuclear factor $1 \alpha$ mutations," Journal of Internal Medicine, vol. 274, no. 3, pp. 263-272, 2013.

[16] M. Pontoglio, J. Barra, M. Hadchouel et al., "Hepatocyte nuclear factor 1 inactivation results in hepatic dysfunction, phenylketonuria, and renal Fanconi syndrome," Cell, vol. 84, no. 4, pp. 575-585, 1996.

[17] T. G. Araújo, A. G. de Oliveira, J. F. Vecina et al., "Parkinsonia aculeata (Caesalpineaceae) improves high-fat diet-induced insulin resistance in mice through the enhancement of insulin signaling and mitochondrial biogenesis," Journal of Ethnopharmacology, vol. 183, pp. 95-102, 2016.

[18] T. G. Araújo, A. G. Oliveira, J. F. Vecina et al., “Treatment with Parkinsonia aculeata combats insulin resistance-induced oxidative stress through the increase in PPAR $\gamma / \mathrm{CuZn}$-SOD axis expression in diet-induced obesity mice," Molecular and Cellular Biochemistry, vol. 419, no. 1-2, pp. 93-101, 2016.

[19] X. Z. Ruan, J. F. Moorhead, J. L. Tao et al., "Mechanisms of dysregulation of low-density lipoprotein receptor expression in vascular smooth muscle cells by inflammatory cytokines," Arteriosclerosis, Thrombosis, and Vascular Biology, vol. 26, no. 5, pp. 1150-1155, 2006.

[20] K. Makki, P. Froguel, and I. Wolowczuk, "Adipose tissue in obesity-related inflammation and insulin resistance: cells, cytokines, and chemokines," ISRN Inflammation, vol. 2013, Article ID 139239, 12 pages, 2013.

[21] M. Kosmalski, L. Mokros, P. Kuna, A. Witusik, and T. Pietras, "Changes in the immune system-the key to diagnostics and therapy of patients with non-alcoholic fatty liver disease," Central-European Journal of Immunology, vol. 43, no. 2, pp. 231-239, 2018.

[22] Y. H. Lee, B. Sauer, and F. J. Gonzalez, "Laron dwarfism and non-insulin-dependent diabetes mellitus in the Hnf- $1 \alpha$ knockout mouse," Molecular and Cellular Biology, vol. 18, no. 5, pp. 3059-3068, 1998.

[23] J.-M. Servitja, M. Pignatelli, M. A. Maestro et al., "Hnf1 $\alpha$ (MODY3) controls tissue-specific transcriptional programs and exerts opposed effects on cell growth in pancreatic islets and liver," Molecular and Cellular Biology, vol. 29, no. 11, pp. 2945-2959, 2009. 
[24] M. Pontoglio, S. Sreenan, M. Roe et al., "Defective insulin secretion in hepatocyte nuclear factor 1alpha-deficient mice," Journal of Clinical Investigation, vol. 101, no. 10, pp. 22152222, 1998.

[25] M. A. Garcia-Gonzalez, C. Carette, A. Bagattin et al., "A suppressor locus for MODY3-diabetes," Scientific Reports, vol. 6 , no. 1, article 33087, 2016.

[26] T. Kakuma, Y. Lee, M. Higa et al., "Leptin, troglitazone, and the expression of sterol regulatory element binding proteins in liver and pancreatic islets," Proceedings of the National Academy of Sciences of the United States of America, vol. 97, no. 15, pp. 8536-8541, 2000.

[27] J. K. Reddy and M. S. Rao, "Lipid metabolism and liver inflammation. II. Fatty liver disease and fatty acid oxidation," American Journal of Physiology-Gastrointestinal and Liver Physiology, vol. 290, no. 5, pp. G852-G858, 2006.

[28] A. V. Contreras, N. Torres, and A. R. Tovar, "PPAR- $\alpha$ as a key nutritional and environmental sensor for metabolic adaptation," Advances in Nutrition, vol. 4, no. 4, pp. 439-452, 2013.

[29] B. Sun, Y. Jia, J. Hong et al., "Sodium butyrate ameliorates high-fat-diet-induced non-alcoholic fatty liver disease through peroxisome proliferator-activated receptor $\alpha$-mediated activation of $\beta$ oxidation and suppression of inflammation," Journal of Agricultural and Food Chemistry, vol. 66, no. 29, pp. 76337642, 2018.

[30] Y. Li, M. Zalzala, K. Jadhav et al., "Carboxylesterase 2 prevents liver steatosis by modulating lipolysis, endoplasmic reticulum stress, and lipogenesis and is regulated by hepatocyte nuclear factor 4 alpha in mice," Hepatology, vol. 63, no. 6, pp. 18601874, 2016.

[31] Q. Ni, K. Ding, K. Q. Wang et al., "Deletion of HNF1 $\alpha$ in hepatocytes results in fatty liver-related hepatocellular carcinoma in mice," FEBS Letters, vol. 591, no. 13, pp. 1947-1957, 2017.

[32] B. F. Voight, L. J. Scott, V. Steinthorsdottir et al., "Twelve type 2 diabetes susceptibility loci identified through large-scale association analysis," Nature Genetics, vol. 42, no. 7, pp. 579$589,2010$.

[33] H. Qian, X. Deng, Z. W. Huang et al., “An HNF1 $\alpha$-regulated feedback circuit modulates hepatic fibrogenesis via the crosstalk between hepatocytes and hepatic stellate cells," Cell Research, vol. 25, no. 8, pp. 930-945, 2015.

[34] H. Inoue, W. Ogawa, M. Ozaki et al., "Role of STAT-3 in regulation of hepatic gluconeogenic genes and carbohydrate metabolism in vivo," Nature Medicine, vol. 10, no. 2, pp. 168-174, 2004.

[35] S. Kinoshita, W. Ogawa, Y. Okamoto et al., "Role of hepatic STAT3 in the regulation of lipid metabolism," The Kobe Journal of Medical Sciences, vol. 54, no. 4, pp. E200-E208, 2008. 


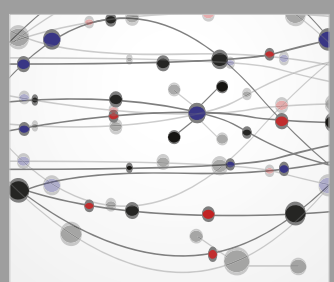

The Scientific World Journal
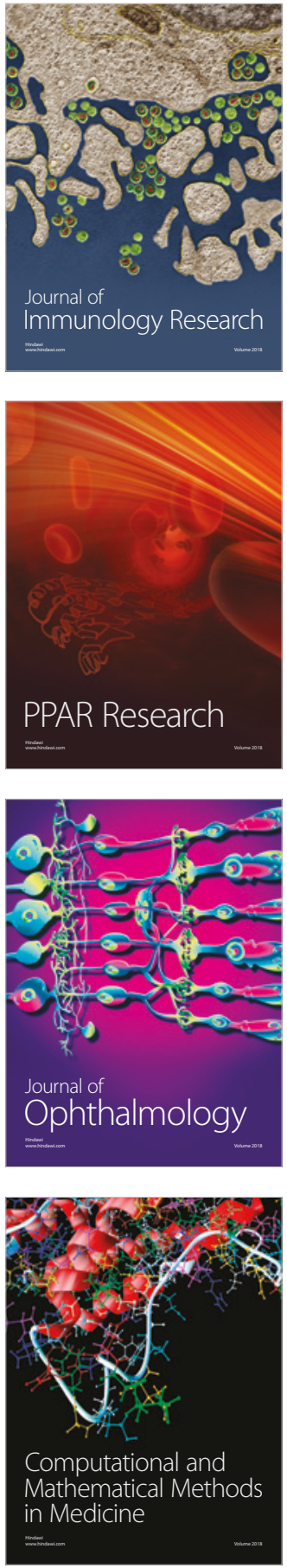

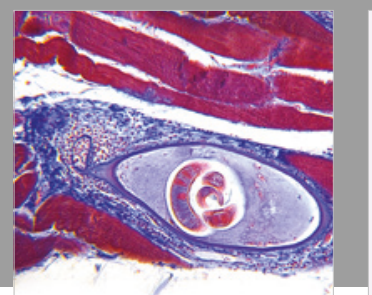

Gastroenterology Research and Practice

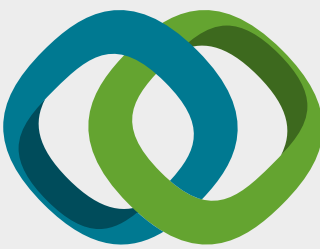

\section{Hindawi}

Submit your manuscripts at

www.hindawi.com
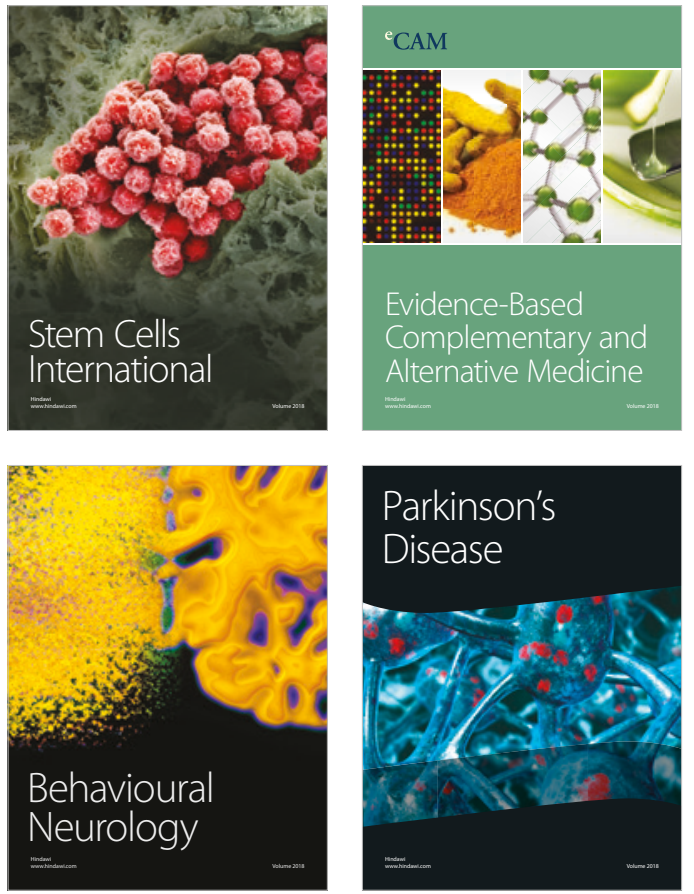

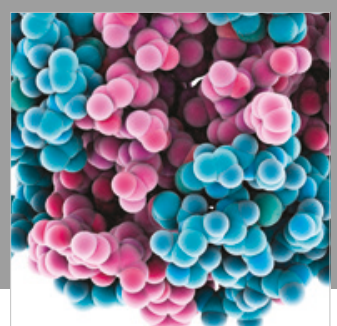

ournal of

Diabetes Research

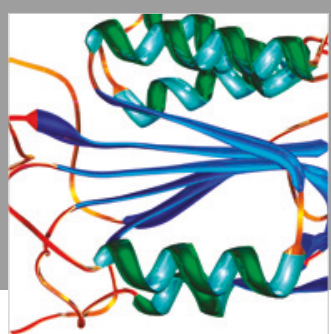

Disease Markers
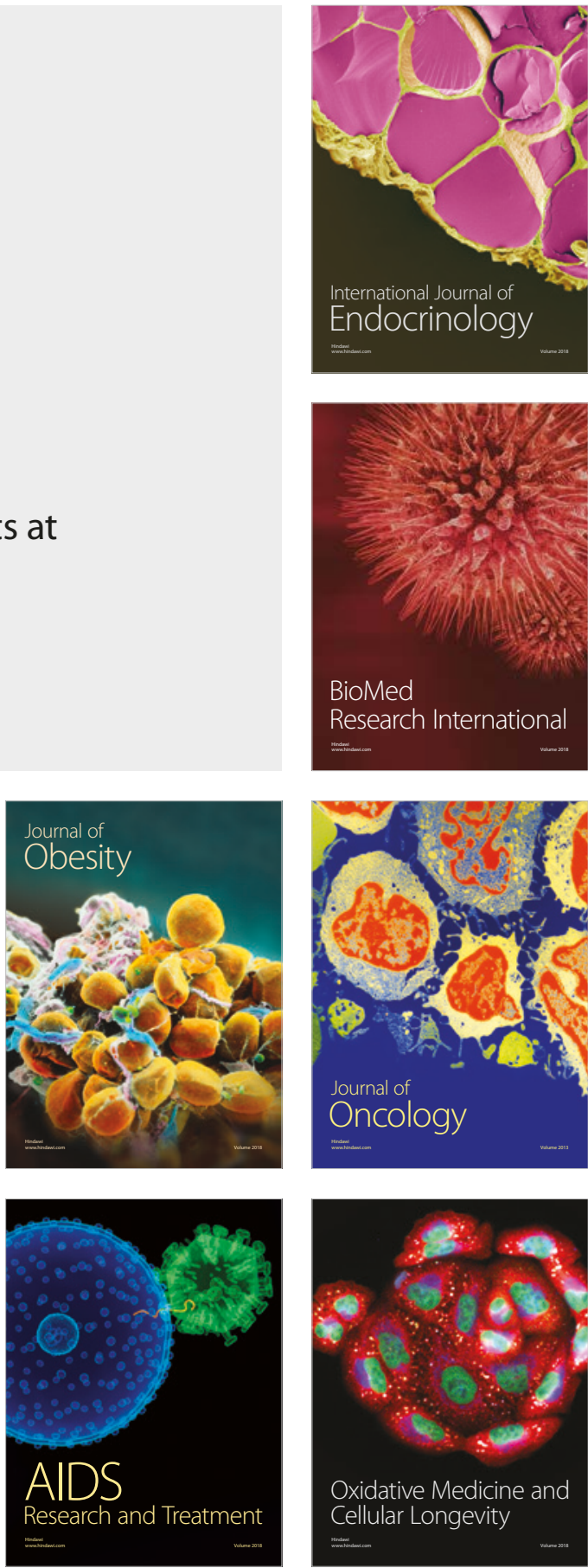